\title{
Numerical investigation of pool boiling on a staggered tube bundle for different working fluids
}

\author{
A. Ahmadpour ${ }^{1}$, S. M. A. Noori Rahim Abadi ${ }^{2}$, J. P. Meyer ${ }^{2}$ \\ ${ }^{1}$ Department of Mechanical Engineering, Amirkabir University of Technology, Tehran, Iran \\ ${ }^{2}$ Department of Mechanical and Aeronautical Engineering, University of Pretoria, Pretoria, \\ South Africa
}

\begin{abstract}
:
In the present work, a numerical approach is proposed to simulate two phase pool boiling on a staggered tube bundle. The simulations are carried out using the Eulerian-Eulerian framework for two phase flows, accounting for the nucleate pool boiling on the surface of the tube bundle. A favourable agreement was reported between the numerical results and previously published experimental data for pool boiling heat transfer. The numerical results are presented for four working fluids, including water, ethanol, R134a and R22, each at three different saturation temperatures. The effect of saturation temperature, the variation in the heat transfer within the tube bundle and the effect of the working fluid are fully addressed.
\end{abstract}

Keywords: Pool boiling, Numerical simulation, Tube bundle, Eulerian-Eulerian.

*Corresponding author's email: josua.meyer@up.ac.za;

Tel.: +270 12420 3104; Fax: +27 012362 5124; 


\section{Introduction}

High performance heat exchanging equipment is extremely desired for various applications found in power, petrochemical and chemical plants. Among these thermal devices, shell and tube heat exchangers are of great importance due to their wide spread usage in various industries. The heat transfer enhancement in shell and tube heat exchangers could be attained using a boiling liquid as the working fluid due to a noticeably higher heat transfer coefficient (HTC) of the phase change phenomenon (Ribatski and Thome, 2007). Boiling commonly occurs on the shell side and over the tube bundles with an in-line or staggered arrangement. Therefore, the study of the boiling heat transfer on tube bundles has attracted a vast interest from the scientific community.

The boiling on a tube bundle could occur in the absence or presence of forced fluid motion. In the absence of forced fluid motion, pool boiling occurs on the tube surfaces as the result of vapour bubble nucleation and departure. Moreover, a natural circulation of the boiling liquid is also present due to the existing temperature gradient in the flow field. The pool boiling fluid flow and heat transfer on the tube bundles is a complex physical phenomenon, which is the main heat transfer mechanism in passive type heat exchangers for nuclear reactors, flooded evaporators and thermo-syphon reboilers (Swain and Das, 2014). Laboratory scaled experimental measurements have been the predominant methodology to study the pool boiling heat transfer of tube bundles.

An early attempt to investigate the pool boiling on a tube bundle was the experimental work of Fujita and Hidaka (1998), in which the nucleate boiling of Freon-113 was investigated on staggered and in-line bundles. The experimental results showed that the pool boiling heat transfer characteristics of the lowest tubes were similar to an isolated tube. However, the heat 
transfer coefficient increased in the vertical direction within the tube bundle. This rise in the heat transfer coefficient weakened as the heat flux increased, and for a high enough value of the heat flux, a nearly constant heat transfer coefficient existed throughout the bundle. The same behaviour was reported for pool boiling of atmospheric water on an in-line $5 \times 3$ tube bundle (Gupta, 2005). Additionally, it was observed that increasing the number of rows in a bundle and decreasing the pitch-to-diameter ratio enhanced the bundle effect. In a subsequent work, Gupta et al. (2010) proposed a power-law type correlation for the variation in the heat transfer coefficient along the height of a tube bundle for the partial pool boiling regime when water was used as the working fluid.

In another work, Kumar et al. (2002) studied the pool boiling heat transfer on a pair of vertically aligned heated tubes that were submerged into a bath of atmospheric water as the boiling liquid. It was concluded that the detached vapour bubbles from the lower tube surface intensified the turbulence around the upper tube and, subsequently, increased the upper tube heat transfer coefficient while the heat transfer of lower tube was not affect by the presence of the upper tube.

The conclusion of Kumar et al. (2002) was further corroborated by Hsieh et al. (2003), who studied the pool boiling heat transfer of R-134a on in-line and staggered tube bundles. It was shown that the overall heat transfer coefficient for a tube bundle was higher than the corresponding value for an isolated heated tube. This heat transfer enhancement was quantified using the bundle effect (the ratio of the heat transfer coefficients for a tube bundle to an isolated tube with an identical heat flux). It was deduced that the bundle effect is strongly dependent on the arrangement of the tubes within a tube bundle, and the heat transfer coefficient decreases for all the arrangements when heat flux increases. 
According to the experimental measurements of Da Silva et al. (2007), the ratio of the heat transfer coefficient in two consecutive rows of a vertical array of horizontal tubes first increased with the heat flux to reach its maximum value for a relatively low heat flux (maximum values up to 2 are reported for R123). Subsequently, this ratio decreased with the heat flux and eventually tended to unity for a relatively large heat flux. A proper correlation was proposed for the heat transfer coefficient ratio.

The effects of the saturation temperature of the boiling liquid on the pool boiling heat transfer over tube bundles were examined by Ribatski and Thome (2006). It was reported that the effects of the saturation temperature on the heat transfer coefficient are almost negligible. However, the measurement of the pool boiling heat transfer coefficient on a staggered tube bundle for three working fluids, including water, methanol and R141b, showed the obvious superiority of water (Krasowski and Cieslinski, 2011). Moreover, the heat transfer coefficient increased as the saturation pressure was increased. More recently, Kang (2016) examined the effects of the inclination angle on the pool boiling on tube bundles. A notable decrease in the heat transfer coefficient was observed with the inclination angle.

A brief survey of the preceding studies revealed that the experimental examination of the pool boiling over tube bundles has reached a mature enough state so that a reliable database for the subject is available within the scientific literature. In contrast, the numerical simulations of the pool boiling on smooth tube bundles has yet to be developed. To the best of our knowledge, the only numerical attempt to tackle the pool boiling heat transfer problem on a smooth tube was the 3D CFD simulation of Minocha et al. (2016). In this study, the pool boiling on an inclined isolated smooth tube was simulated using a two-phase mixture model. 
A desirable agreement was reported between the obtained numerical results and the available experimental data.

The success of Minocha's CFD simulation of pool boiling fluid flow, heat transfer and the importance of numerical modelling and simulation as an effective design and analysis tool motivated us to explore the numerical simulation of pool boiling on tube bundles. Therefore, the present work for the first time provides a numerical approach based on an EulerianEulerian description of two phase flows and is validated against experimental data for the simulation of pool boiling over tube bundles. Numerical results are presented for four different working fluids, including water, ethanol, R-134a and R-22. The present manuscript is organized as follows, in Sections 2 and 3, the governing equations of the pool boiling problem and the adapted numerical method are outlined. Subsequently, Section 4 gives the presentation of the obtained numerical results. Finally, the work is concluded in Section 5 by highlighting its major findings.

\section{Governing equations}

In the present work, an Eulerian-Eulerian framework is adapted for the numeric simulation of the boiling flow field. Therefore, two separate sets of conservative equations for mass, linear momentum and energy are solved for the liquid and gaseous phases as follows (Drew, 1983; Yeoh and Tu, 2010),

$\frac{\partial}{\partial t}\left(\alpha^{k} \rho^{k}\right)+\nabla \cdot\left(\alpha^{k} \rho^{k} \vec{u}^{k}\right)=\dot{\Gamma}^{k p}-\dot{\Gamma}^{p k}$ 
$\frac{\partial}{\partial t}\left(\alpha^{k} \rho^{k} \vec{u}^{k}\right)+\nabla \cdot\left(\alpha^{k} \rho^{k} \vec{u}^{k} \vec{u}^{k}\right)=-\alpha^{k} \nabla P+\nabla \cdot \tau^{k}+\alpha^{k} \rho^{k} \vec{g}+\dot{\Gamma}^{p k} \vec{u}^{k}-\dot{\Gamma}^{k p} \vec{u}^{k}+S_{u}{ }^{k}$

$\frac{\partial}{\partial t}\left(\alpha^{k} \rho^{k} h^{k}\right)+\nabla \cdot\left(\alpha^{k} \rho^{k} \vec{u}^{k} h^{k}\right)=\alpha^{k} \frac{\partial P}{\partial t}-\nabla \cdot q^{k}+Q^{\text {exchange,pk}}+\dot{\Gamma}^{p k} h^{k}-\dot{\Gamma}^{k p} h^{p}+S_{h}{ }^{k}$

Where superscript " $k$ " denotes the k-th phase (which could be liquid $(l)$ or vapour $(v)$ ), $\rho^{k}$ is the density, $\dot{\Gamma}^{k}$ is the mass transfer rate between phases, $P$ is pressure, $\vec{u}^{k}$ is the velocity vector and $\alpha^{k}$ is the volume fraction of the k-th phase. Additionally, $g$ is the gravitational acceleration vector and $S_{u}{ }^{k}$ is the inter-phase momentum transfer term, $S_{h}{ }^{k}$ is the interphase energy transfer term, $h^{k}$ is the enthalpy, $q^{k}$ is the heat flux, $t$ is the time, $\tau$ is the shear stress and $Q^{\text {exchange,pk }}$ is the direct heat transfer to phase " $k$ " from the other phases and can be calculated as:

$Q^{\text {exchange, } p k}=h_{\text {interfacial }} A_{\text {interfacial }}\left(T_{p}-T_{k}\right)$

(4)

Where $T, h_{\text {interfacial }}$ and $A_{\text {interfacial }}$ are the fluid temperature, interface heat transfer coefficient (see Eq. 20) and interfacial area concentration respectively. The interfacial area concentration can be calculated as:

$A_{\text {interfacial }}=\min \left(1,0.57, \pi D_{w}^{2} N_{w}\right)$ 
We use the realisable $k$ - $\varepsilon$ method to model liquid- and gas- phase turbulence as its suitable performance for the simulation of the pool boiling has been approved previously approved (Minocha et al., 2016). The mathematical formulation for the method $k$ - $\varepsilon$ is presented by (Avetissian et al., 2005, 2008):

$$
\frac{\partial\left(\alpha^{k} \rho^{k} k^{k}\right)}{\partial t}+\nabla \cdot\left(\alpha^{k} \rho^{k} k^{k} \vec{u}^{k}\right)=\nabla \cdot\left(\alpha^{k} \frac{\mu_{T}^{k}}{\sigma_{k}} \nabla k^{k}\right)+\alpha^{k} \tau_{T}^{k}: \nabla \vec{u}^{k}-\alpha^{k} \rho^{k} \varepsilon^{k}+S_{k^{k}}^{i n t}
$$

(6)

$$
\frac{\partial\left(\alpha^{k} \rho^{k} \varepsilon^{k}\right)}{\partial t}+\nabla \cdot\left(\alpha^{k} \rho^{k} \varepsilon^{k} \vec{u}^{k}\right)=\nabla \cdot\left(\alpha^{k} \frac{\mu_{T}^{k}}{\sigma_{\varepsilon}} \nabla \varepsilon^{k}\right)+\alpha^{k} \frac{\varepsilon^{k}}{k^{k}}\left(C_{\varepsilon 1} \tau_{T}^{k}: \nabla \vec{u}^{k}-C_{\varepsilon 2} \rho^{k} \varepsilon^{k}\right)+S_{\varepsilon^{k}}^{i n t}
$$

$$
\tau_{T}^{k}=\mu_{T}^{k}\left[\nabla \vec{u}^{k}+\left(\nabla \vec{u}^{k}\right)^{t}-\frac{2}{3}\left(\nabla \cdot \vec{u}^{k}\right) I\right]-\frac{2}{3} \rho^{k} k^{k} I
$$

In Eqs. 6 and 7, $k$ and $\varepsilon$ denote the turbulence kinetic energy and dissipation rate, respectively. The constants in Eqs. 6 and 7 are set to the followings (Minocha et al., 2016):

$C_{\mu}=0.09, \quad \sigma_{k}=1.0, \quad \sigma_{\varepsilon}=1.3, \quad C_{\varepsilon 1}=1.44, \quad C_{\varepsilon 2}=1.92$

Ultimately, the interaction of nucleated bubbles with the turbulent fluid flow of the liquid is accounted for by using two source terms of $S_{k^{l}}^{\text {int }}$ and $S_{\varepsilon^{l}}^{\text {int }}$, which are expressed by the following equations (Ahmadpour et al., 2016): 
$S_{k^{l}}^{\text {int }}=-\left(F^{l, d r a g}+F^{l, v m}\right) \cdot\left(\vec{u}^{v}-\vec{u}^{l}\right)$

(10)

$S_{\varepsilon^{l}}^{i n t}=C_{\varepsilon 3} \frac{S_{k^{l}}^{i n t}}{\tau_{b}}, \quad \tau_{b}=\left(\frac{\left(d^{v}\right)^{2}}{\varepsilon^{l}}\right)^{1 / 3}$

The momentum interaction of the boiling liquid and the nucleated vapour bubbles are given by Eq. 12 as the superposition of the drag and lift forces $\left(F^{k, \text { Drag }}\right.$ and $\left.F^{k, l i f t}\right)$ together with the turbulent dispersion $\left(F^{k \text {,dispersion }}\right)$ and wall lubrication $\left(F^{k, \text { wall }}\right)$ effects,

$S^{k}=F^{k, \text { drag }}+F^{k, \text { lift }}+F^{k, \text { dispersion }}+F^{k, \text { wall }}$

In the present study, the drag force is calculated from the model of Clift et al. (1978) as (the superscript "l" denotes the dispersed phase),

$F^{k, d r a g}=\frac{1}{8} C_{D} a_{i f} \rho^{k}\left|u^{l}-u^{k}\right|\left(u^{l}-u^{k}\right)$

$C_{D}=\max \left[\min \left(C_{D, \text { ellipse }}, C_{D, \text { cap }}\right), C_{D_{\text {Sphere }}}\right]$

$C_{D_{\text {Sphere }}}=\left\{\begin{array}{cl}\frac{24}{\operatorname{Re}} & \operatorname{Re} \leq 0.01 \\ 24 \frac{\left(1+0.15 \operatorname{Re}^{0.687}\right)}{\operatorname{Re}} & \operatorname{Re}>0.01\end{array} ; C_{D, \text { cap }}=\frac{8}{3} ; C_{D, \text { ellipse }}=\frac{4}{3} \frac{g d^{l}}{U_{t}^{2}} \frac{\left(\rho^{k}-\rho^{l}\right)}{\rho^{l}} ;\right.$ 
$\operatorname{Re}=\frac{\rho^{k}\left|u^{l}-u^{k}\right| d^{l}}{\mu^{k}} ; U_{t}=\frac{\mu^{k}}{\rho^{k} d^{l}} M o^{-0.149}(J-0.857) ; M o=\frac{\left(\mu^{k}\right)^{4} g\left(\rho^{k}-\rho^{l}\right)}{\left(\rho^{k}\right)^{2} \sigma^{3}}$

$J=\left\{\begin{array}{cc}0.94 H^{0.757} & 2<H \leq 59.3 \\ 3.42 H^{0.441} & H>59.3\end{array} ; \quad H=\frac{4}{3} E o M o^{-0.149}\left(\frac{\mu^{k}}{0.0009}\right)^{-0.14}\right.$

$E o=\frac{g\left(\rho^{k}-\rho^{l}\right)\left(d^{l}\right)^{2}}{\sigma}$

and $R e$ is Reynolds number, $M o$ is Morton number, and $E o$ is the Eotvos number. The lift force is approximated using the Tomiyama model (Tomiyama, 1998) as it is presented in Eq. 16:

$F^{k, l i f t}=-F^{l, l i f t}=C_{L} \alpha^{l} \rho^{k}\left(u^{l}-u^{k}\right) \times\left(\nabla \times u^{k}\right)$

$C_{L}=\left\{\begin{array}{cc}\min \left[0.288 \tanh (0.121 R e), f\left(E o_{d}\right)\right] & E o<4 \\ f\left(E o_{d}\right)=0.00105 E o_{d}{ }^{3}-0.0159 E o_{d}{ }^{2}-0.0204 E o_{d}+0.474 & 4<E o<10 \\ -0.29 & E o>10\end{array}\right.$

$E o_{d}=\frac{g\left(\rho^{k}-\rho^{l}\right)\left(d^{l}\right)^{2}}{\sigma}\left(1+0.163 E o^{0.757}\right)^{2 / 3}$

To account for wall lubrication and turbulent dispersion forces, the formulation proposed by Antal et al. (1991) and Burns et al. (2004) is employed, respectively, 


$$
\begin{aligned}
& F^{k, w a l l}=C_{w} \rho^{k} \alpha^{l}\left|u^{l}-u^{k}\right|^{2} n_{w} \\
& C_{w}=\max \left(0, \frac{C_{w 1}}{d^{l}}+\frac{C_{w 2}}{y_{w}}\right) ; C_{w 1}=-0.01 ; C_{w 2}=0.05
\end{aligned}
$$

$$
F^{k, \text { dispersion }}=-F^{l, d i s p e r s i o n}=C_{D} \frac{\mu_{T}^{l}}{\rho^{l} S c_{b}}\left(\frac{\nabla \alpha^{l}}{\alpha^{l}}-\frac{\nabla \alpha^{k}}{\alpha^{k}}\right)
$$

The inter-phase heat transfer coefficient, $h_{\text {interfacial}}$, is calculated from the correlation of Tomiyama (1998) for the Nusselt number in the turbulent bubbly flow as follows,

$$
N u^{k}=2.0+0.15 \operatorname{Re}^{0.8} \operatorname{Pr}^{0.5}
$$

To model the nucleate pool boiling on solid surfaces, the RPI model of Kurul and Podowski (1991) is adapted. In this model, the wall heat flux consists of three components, including the convective heat flux between the solid surface and its surrounding fluid $\left(\dot{q}_{c}\right)$, the latent heat flux of vaporization $\left(\dot{q}_{E}\right)$, and the quenching flux due to bubble departure from the surface $\left(\dot{q}_{Q}\right)$. The convective heat flux occurs on the wetted portion of the solid surface and is proportional to the temperature difference between the solid surface and its surrounding liquid. Therefore, this portion of total heat flux could be given by (Del Valle and Kenning, 1985),

$\dot{q}_{C}=h_{C}\left(T_{W}-T_{l}\right)\left(1-A_{b}\right)$ 


$$
\begin{aligned}
& A_{b}=\min \left(1, K_{D K} \frac{N_{W} \pi D_{W}^{2}}{4}\right) ; K_{D K}=4.8 \exp \left(-\frac{1}{80} \frac{\rho_{l} C_{p, l}\left(T_{s a t}-T_{l}\right)}{\rho_{v} h_{l v}}\right) \\
& D_{W}=\min \left(0.0014,0.0006 \exp \left(-\frac{\Delta T_{W}}{45}\right)\right)
\end{aligned}
$$

Where $h_{c}$ is the single-phase heat transfer coefficient, $T_{w}-T_{l}$ is the wall and liquid temperature difference, $A_{b}$ is the part of the wall surface covered by nucleate bubbles. $T_{\text {sat }}$ is the saturation temperature, $D_{w}$ is the bubble departure diameter, and $N_{w}$ is the nucleate site density computed from the correlation of Lemmert and Chawla (1977) as follows,

$N_{W}=C^{n}\left(T_{w}-T_{s a t}\right)^{n} ; C=210, n=1.805$

The evaporative heat flux is proportional to the mass of the nucleated bubbles and could be approximated using the nucleation site density,

$\dot{q}_{E}=\frac{\pi}{6} D_{W}^{3} N_{W} \rho_{v} h_{l v}$

Finally, $\dot{q}_{Q}$ is related to effective temperature gradient using Cole's (1960) model for the bubble departure period $(\tau)$ as, 


$$
\begin{aligned}
& \dot{q}_{Q}=\frac{k_{l}}{\sqrt{\frac{k_{l}}{\rho_{l} C_{p, l}} \tau}}\left(T_{W}-T_{l}\right) \\
& \frac{1}{\tau}=\sqrt{\frac{4 g\left(\rho_{l}-\rho_{v}\right)}{3 \rho_{l} D_{W}}}
\end{aligned}
$$

The mass transfer rate between liquid and vapour phases occurs in two distinct regions, near the hot wall and in the bulk liquid. The mass transfer near the hot wall can be calculated by:

$$
\dot{m}^{1}=\frac{\dot{q}_{E}}{h_{l v}+c_{p, l}\left(T_{s a t}-T_{l}\right)}
$$

The mass transfer rate at the bulk saturated liquid region can be determined as:

$$
\dot{m}^{2}=\frac{\dot{q}_{l}+\dot{q}_{v}}{h_{l v}}
$$

$$
\dot{q}_{l}=\frac{k_{l} N u_{l}}{D_{w}}\left(T_{s a t}-T_{l}\right) ; \dot{q}_{v}=\frac{\alpha_{v} \rho_{v} c_{p, v}}{\delta t}\left(T_{s a t}-T_{v}\right)
$$

Where $\delta t$ denotes the time scale set to 0.05 (Minocha et al., 2016). 


\section{Numerical method}

\subsection{Physical domain and problem description}

In the present work, a 2D rectangular domain as part of a pressurized vessel is considered for the numerical simulations of the pool boiling on tube bundles. The size of the flow domain is set at $0.33 \times 0.43 \mathrm{~m}$ and the fluid inlet/outlet is allowed at the top/bottom side of the domain, while the other sides of the domain are considered as adiabatic solid walls. A bundle of 45 circular smooth tubes in a staggered arrangement with a diameter of $19.05 \mathrm{~mm}$ and a pitch-todiameter ratio of 1.33 is located at the middle of the physical domain. The boiling fluid must be guided through the bundle using an adiabatic side wall. The side walls are usually fitted by half tubes in order to reduce the by-pass flows (Aprin et al., 2011). The term "adiabatic half round tube" meant that no heat flux were imposed on the surfaces of these fitted tubes and no symmetry is considered for the computational domain. One of the most important issues in the current simulations is to maintain the liquid level and quiescence of the pool during the boiling phenomenon. In this regard various types of boundary conditions as the opening can be considered. In order to check the effect of different boundary conditions on the results, two different pressure inlet boundary conditions are set as the "pressure inlet" boundary condition. Fig. 1 shows the computational domain of these two types of "pressure inlet" boundary conditions. Four test simulations are performed for four different working fluid and operating conditions. Table 1 presents a comparison between the two different cases. The results show that the performance of these two operating conditions are the same, as the maximum deviations between the results are below 1\%. Based on the abovementioned results, all the simulations are performed with the use of computational domain illustrated in Fig. 1(a), because it led to the better convergence and also provided a more quiescent saturated pool condition. 


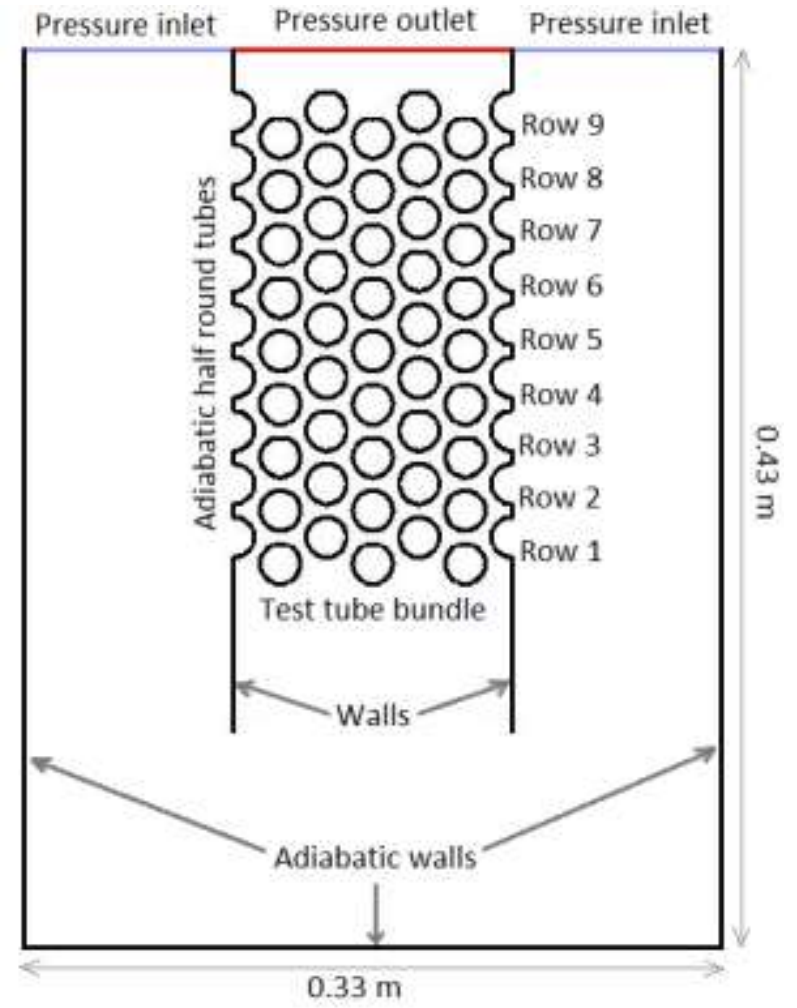

(a)

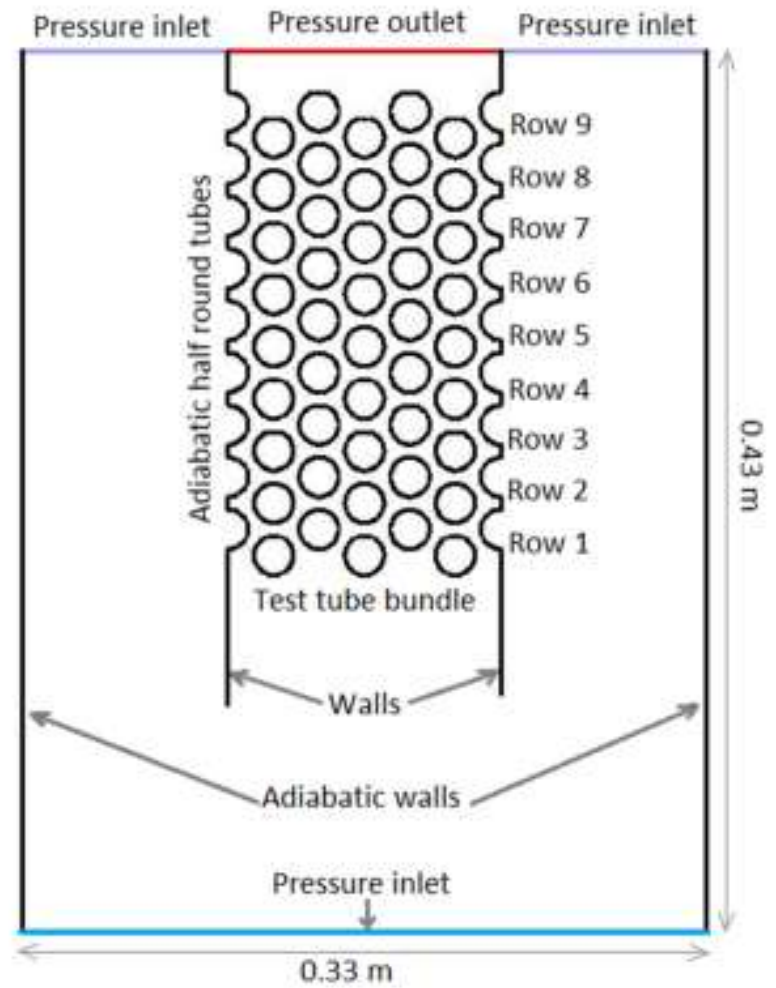

(b)

Figure 1. Computational domain with relevant boundary conditions; (a) type 1, (b) type 2. 
Table 1. Comparison between the results for the two different boundary conditions.

\begin{tabular}{|c|c|c|c|}
\hline Case & $\begin{array}{c}h_{\text {ave }}\left(\mathrm{W} / \mathrm{m}^{2} \mathrm{~K}\right), \text { Bottom } \\
\text { side as wall boundary } \\
\text { condition }\end{array}$ & $\begin{array}{c}h_{\text {ave }}\left(\mathrm{W} / \mathrm{m}^{2} \mathrm{~K}\right) \text {, } \\
\text { Bottom side as pressure inlet } \\
\text { boundary condition }\end{array}$ & Deviation (\%) \\
\hline $\begin{array}{c}\text { Water }\left(q=120 \mathrm{~kW} / \mathrm{m}^{2}, T_{\text {sat }}\right. \\
\left.=100^{\circ} \mathrm{C}\right)\end{array}$ & 15194.2 & 15203.2 & 0.06 \\
\hline $\begin{array}{c}\text { Ethanol }\left(q=5 \mathrm{~kW} / \mathrm{m}^{2}, T_{\text {sat }}=\right. \\
\left.60{ }^{\circ} \mathrm{C}\right)\end{array}$ & 1195.7 & 1198.9 & 0.27 \\
\hline $\begin{array}{c}\mathrm{R} 134 \mathrm{a}\left(q=90 \mathrm{~kW} / \mathrm{m}^{2}, T_{\text {sat }}=\right. \\
\left.20{ }^{\circ} \mathrm{C}\right)\end{array}$ & 13798.0 & 13771.3 & 0.19 \\
\hline $\begin{array}{c}\mathrm{R} 22\left(q=60 \mathrm{~kW} / \mathrm{m}^{2}\right. \\
\left.T_{\text {sat }}=10^{\circ} \mathrm{C}\right)\end{array}$ & 10701.5 & 10703.5 & 0.27 \\
\hline
\end{tabular}

At the initial state, the flow domain is filled with a saturated liquid at a given pressure. The 45 smooth tubes are heated with an adjustable heat flux, and boiling occurs on the surface of the tube bundle. The produced vapour bubbles leave the domain from the upper boundary of the flow channel and compensating saturated liquid enters the domain from its upper side to maintain the liquid at a constant level within the physical domain. Four different liquids were considered as the boiling fluid, including water, ethanol, and the refrigerants R134a and R22. The following assumptions are considered for the numerical simulations:

1. The flow field is transient and turbulent.

2. The properties of each phase are assumed to be constant under the specified operating condition.

3. The simulations are performed at saturation pressure corresponding to the specified working fluids and saturation temperatures.

4. The constant heat flux is set on the copper tubes with the no-slip condition.

5. The contact angle between the liquid and vapour phases on the tube is $80^{\circ}, 35^{\circ}, 6.5^{\circ}$ and $4^{\circ}$ for water, ethanol, R134a and R22, respectively (Barber et al., 2010). 


\subsection{Numerical mesh and flow solver}

The physical domain is discretized using triangular elements as shown in Fig. 2. A detailed mesh refinement study was conducted to acquire the mesh-independent numerical results. As an example, in Fig. 3, the variation of the row-averaged heat transfer coefficient within the tube bundle is depicted for three different numerical grids. As can be seen, using a numerical mesh with 67,833 control volumes is a good compromise between the accuracy and computational costs. This numerical grid is used throughout the manuscript for the simulation of our problem.

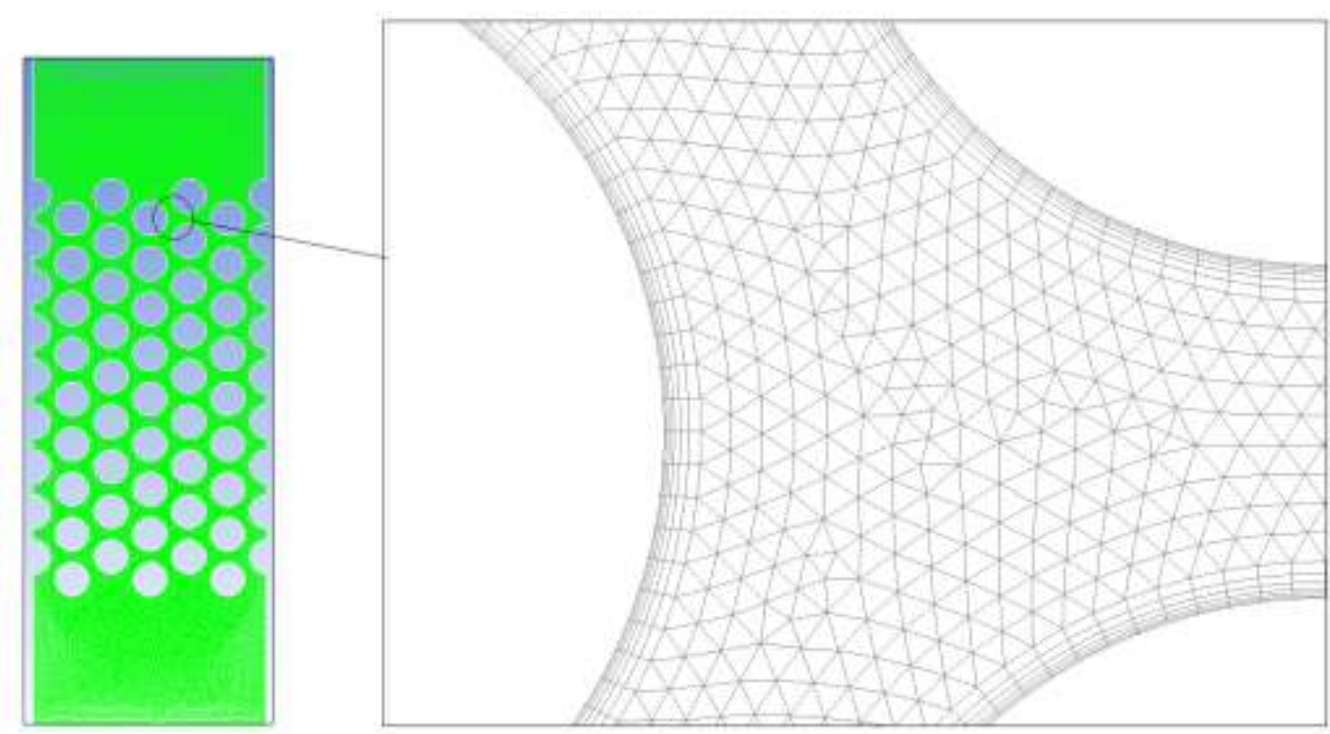

Figure 2. Numerical grid. 


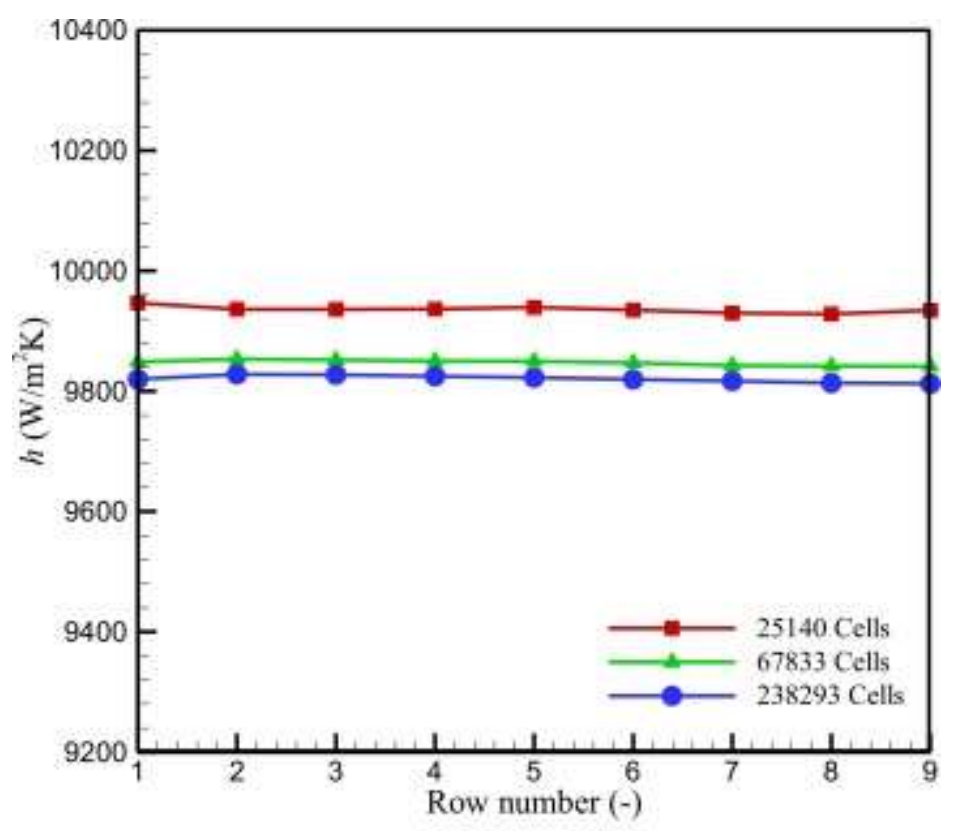

(a)

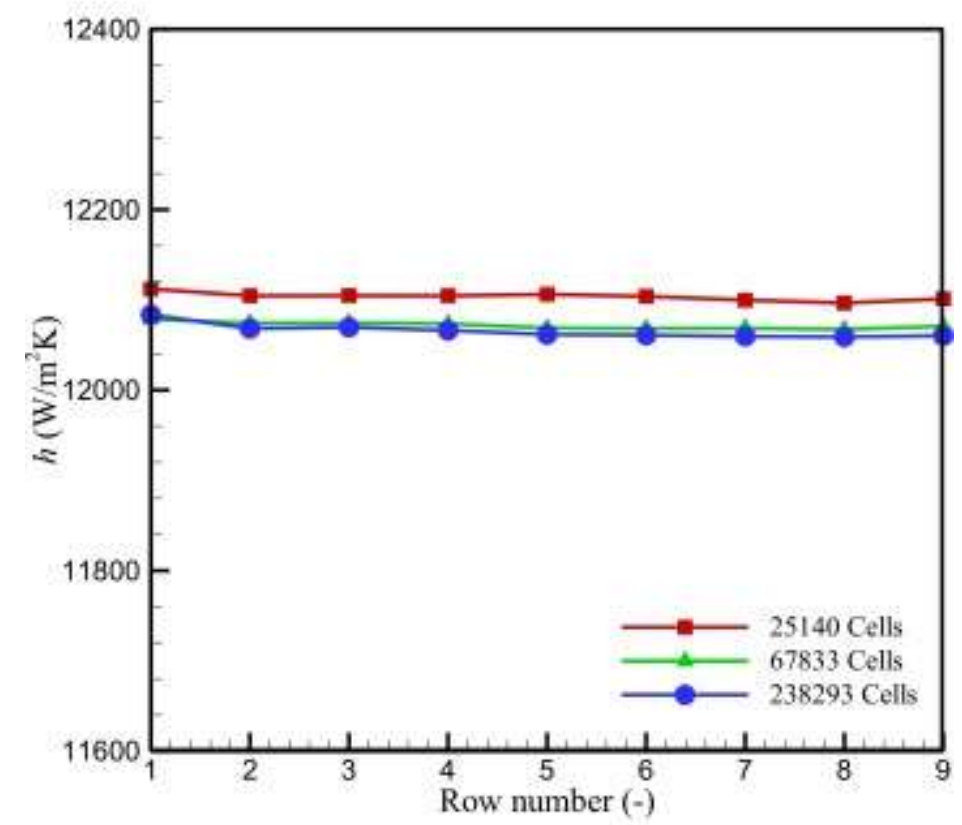

(b)

Figure 3. Effect of grid size on the heat transfer coefficient within the tube bundle (a) $q=60 \mathrm{~kW} / \mathrm{m}^{2}$ and $T_{\text {sat }}$ $=100{ }^{\circ} \mathrm{C}$ for ethanol as working fluid, (b) $q=90 \mathrm{~kW} / \mathrm{m}^{2}$ and $T_{\text {sat }}=10^{\circ} \mathrm{C}$ for R134a as working fluid.

The numerical simulation of pool boiling heat transfer is performed on the commercial CFD software ANSYS FLUENT 17.1 using the numerical approach outlined in Section 2. A pressure-based, fully coupled solver is adapted and diffusive fluxes are calculated by the least 
square cell-based scheme. In all the governing equations, the convective fluxes are approximated by the second-order upwind method. Transient computations are progressed with a time step of $10^{-4} \mathrm{~s}$ and the convergence criterion is set at $10^{-5}$ for each parameters.

\section{Result and Discussion}

In this section, the numerical results concerning the pool boiling on tube bundles are presented and thoroughly discussed. This section commences with the validation of the numerical approach; subsequently, the pool boiling data is provided at low and high pressure ranges. The effects of saturation temperature and the working fluid is also studied.

\subsection{Validation of the numerical method}

To confirm the accuracy and reliability of our numerical method, three validation cases are provided, in which our numerical results are compared to previously published experimental data. The validation cases are summarized as follows:

I. Validation case No. 1 $\left(\mathrm{VC}_{1}\right)$ : Gupta (2005) provided the heat transfer coefficient for pool boiling of water on a $5 \times 3$ inline tube bundle. The reported heat transfer coefficient for the tube located at the bottom row and the central column is compared to the corresponding numerical result.

II. Validation case No. $2\left(\mathrm{VC}_{2}\right)$ : Jung et al. (2003) presented the pool boiling curve of R134a at the saturation temperature of $7^{\circ} \mathrm{C}$ on a single horizontal smooth tube with a $19.0 \mathrm{~mm}$ diameter. The simulated pool boiling curve is compared with the experimental pool boiling curve in the heat flux range of $80-10 \mathrm{~kW} / \mathrm{m}^{2}$.

III. Validation case No. $3\left(\mathrm{VC}_{3}\right)$ : Kang (2016) measured the pool boiling heat transfer coefficient for tandem, vertically aligned smooth tubes with an adjustable inclination angle. Water at atmospheric conditions was used as the working fluid and a 
comparison is drawn for an inclination angle of zero when the lower tube is thermally active.

As can be seen in Fig. 4, a favourable agreement is observed between the experimental data and our numerical results, which firmly corroborates the accuracy of our numerical approach. After validating our numerical method, we proceed here with the presentation of our numerical results. Ass mentioned previously, the pool boiling data is provided for water, ethanol, R134a and R22. To cover a wide range of saturation conditions, the boiling of water and ethanol are investigated in the saturation temperature range of $60-100{ }^{\circ} \mathrm{C}$, which corresponds to the low pressure range of $19-101 \mathrm{kPa}$ for water and $47-226 \mathrm{kPa}$ for ethanol. The boiling of the refrigerants are investigated at the saturation temperature range of $5-20{ }^{\circ} \mathrm{C}$, which corresponds to the high pressure range of $350-570 \mathrm{kPa}$ for R134a and 580-910 $\mathrm{kPa}$ for R22. The thermophysical properties of these working fluids are summarized in Table 2. 
Table 2. Thermophysical properties of water, ethanol, R134a, R22

\begin{tabular}{|c|c|c|c|c|c|c|c|}
\hline $\begin{array}{c}\text { Saturation } \\
\text { Temperature } \\
\left({ }^{\circ} \mathbf{C}\right)\end{array}$ & $\begin{array}{c}\text { Saturation } \\
\text { Pressure } \\
\text { (bar) }\end{array}$ & $\begin{array}{c}\text { Latent } \\
\text { Heat } \\
(\mathrm{kJ} / \mathrm{kg})\end{array}$ & $\begin{array}{l}\text { Liquid/Vapour } \\
\text { Density }\left(\mathbf{k g} / \mathbf{m}^{3}\right)\end{array}$ & $\begin{array}{c}\text { Liquid Viscosity } \\
\qquad\left(10^{-3} \text { Pa.s }\right)\end{array}$ & $\begin{array}{c}\text { Liquid/Vapour } \\
\text { Conductivity } \\
\text { (W/m.K) }\end{array}$ & $\begin{array}{c}\text { Surface } \\
\text { Tension } \\
\left(10^{-3} \mathrm{~N} / \mathrm{m}\right)\end{array}$ & $\begin{array}{c}\text { Liquid/Vapour } \\
\text { Specific Heat } \\
\text { (kJ/kg.K) }\end{array}$ \\
\hline 60 & 0.1992 & 2358 & $983.28 / 0.1302$ & 0.463 & $0.653 / 0.0216$ & 66.07 & $4.185 / 1.924$ \\
\hline 80 & 0.4736 & 2308 & $971.82 / 0.2932$ & 0.351 & $0.669 / 0.0231$ & 62.69 & 4.197/1.969 \\
\hline \multicolumn{8}{|c|}{ Ethanol } \\
\hline 60 & 0.472 & 988.9 & $770 / 0.748$ & 0.588 & $0.171 / 0.0179$ & 19.2 & $2.78 / 1.54$ \\
\hline 80 & 1.086 & 960 & $757 / 1.43$ & 0.432 & 0.169/0.0199 & 17.3 & $3.03 / 1.61$ \\
\hline 100 & 2.26 & 927 & $730 / 3.41$ & 0.318 & $0.167 / 0.0219$ & 15.5 & $3.3 / 1.68$ \\
\hline 20 & 5.7171 & 182.28 & $1225 / 27.778$ & 0.211 & $0.0833 / 0.0133$ & 8.76 & $1.405 / 1.001$ \\
\hline \multicolumn{8}{|c|}{ R22 } \\
\hline 5 & 6.0115 & 199.93 & $1267 / 25.061$ & 2.6025 & $0.0951 / 0.0105$ & 10.95 & $1.186 / 0.769$ \\
\hline 10 & 7.04 & 195.58 & $1249 / 29.917$ & 2.535 & $0.0926 / 0.0107$ & 10.2 & $1.201 / 0.797$ \\
\hline 20 & 9.097 & 156.89 & $1214 / 38.55$ & 2.4 & $0.0875 / 0.0112$ & 8.7 & $1.232 / 0.854$ \\
\hline
\end{tabular}




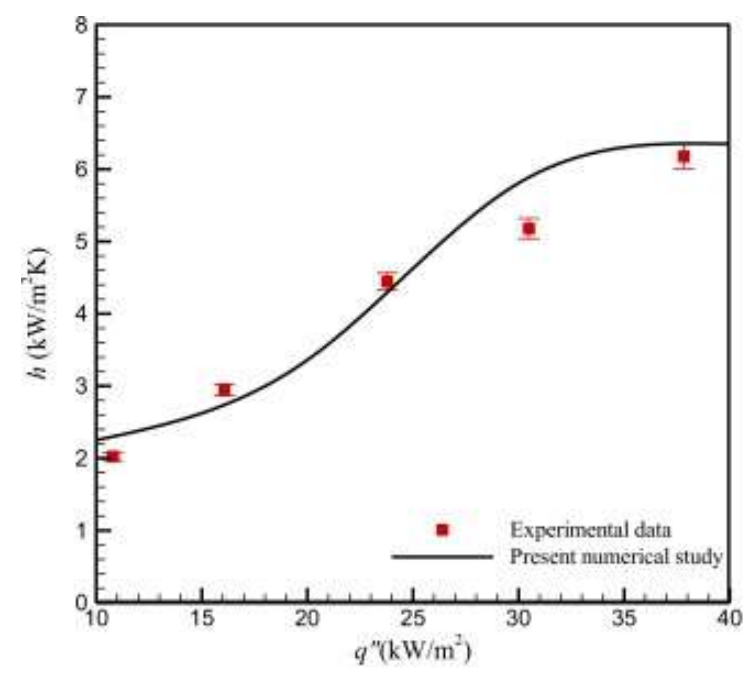

(a)

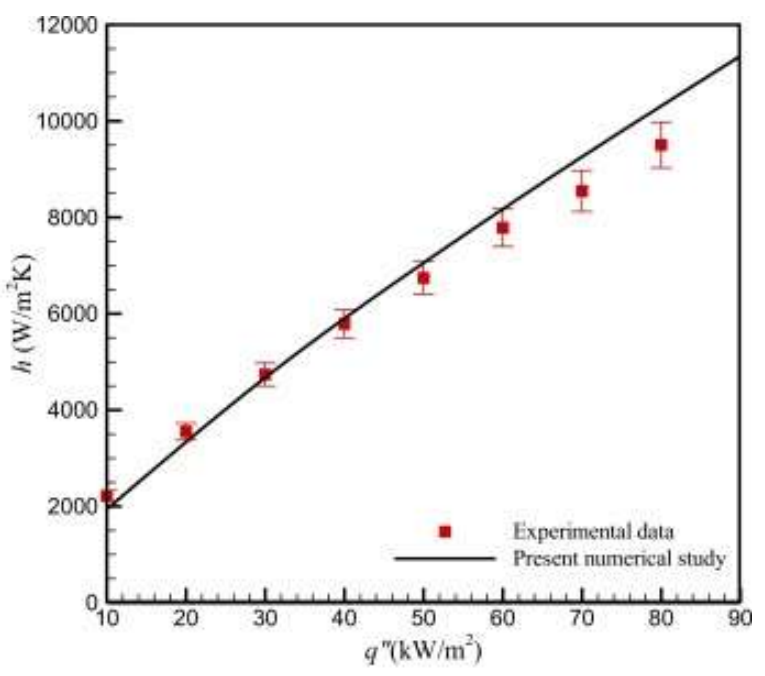

(b)

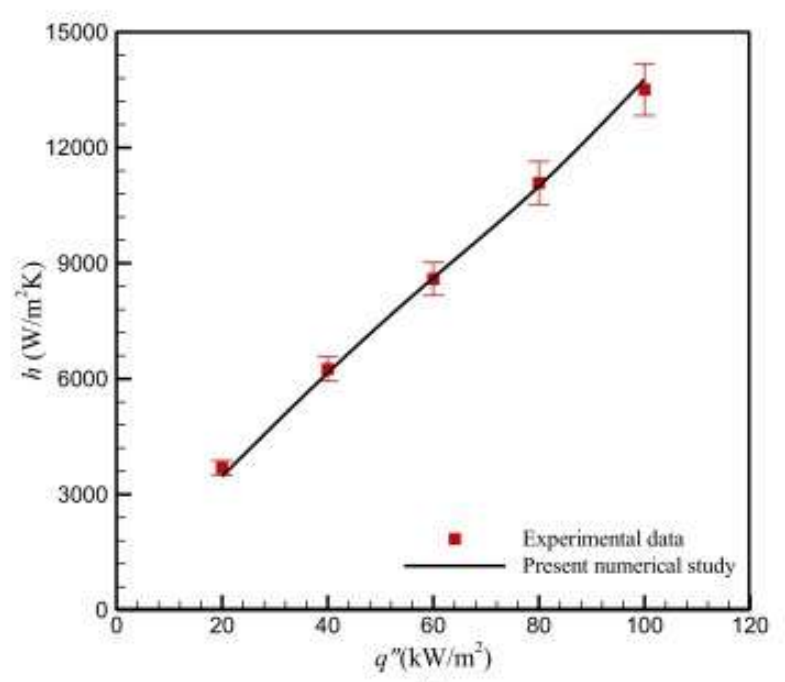

(c)

Figure 4. Comparison of present numerical results with experimental data for: (a) Case $\mathrm{VC}_{1}$ (Gupta, 2005), (b) Case $\mathrm{VC}_{2}$ (Jung et al., 2003), (c) Case $\mathrm{VC}_{3}$ (Kang, 2016).

\subsection{Effect of saturation temperature}

In Fig. 5, the variation in the overall $H T C$ of the tube bundle with the saturation temperature is illustrated for four different heat fluxes. It can be seen from the figure that there is a monotonic increase in the $H T C$ with the saturation temperature (or equivalently the saturation pressure) for all the working fluids studied at each of the heat fluxes. These numerical deductions are in accordance with the experimental measurements of Mudawar and Anderson (1990). Moreover, for the low-pressure region, the effect is more pronounced for water in 
comparison to ethanol. For the refrigerants and in the high-pressure range, an almost linear increase is observed for the $H T C$ with the saturation temperature.

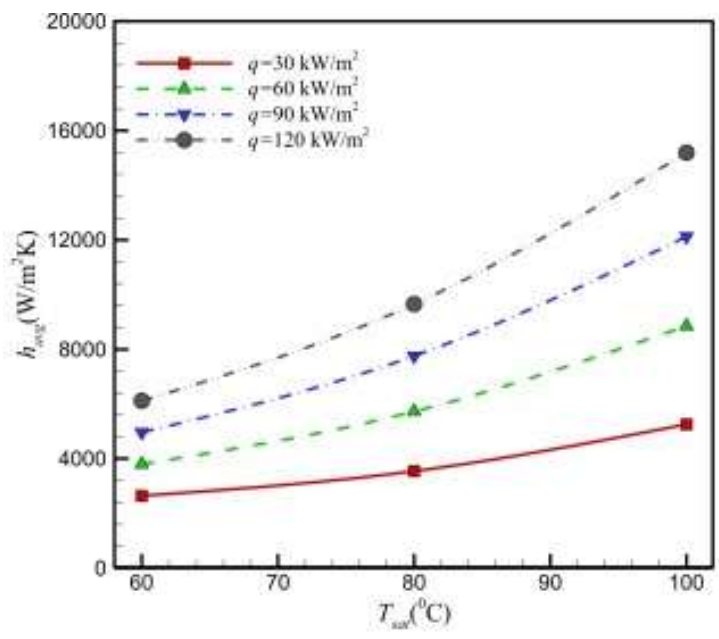

(a)

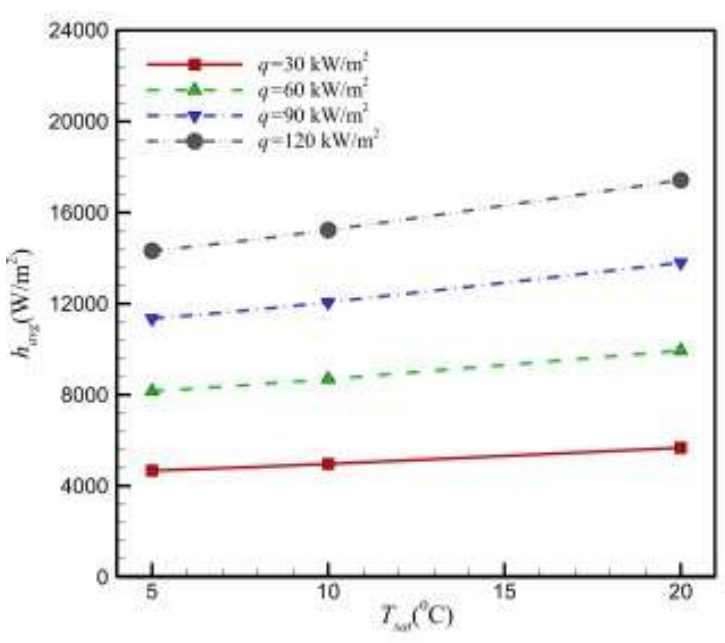

(c)

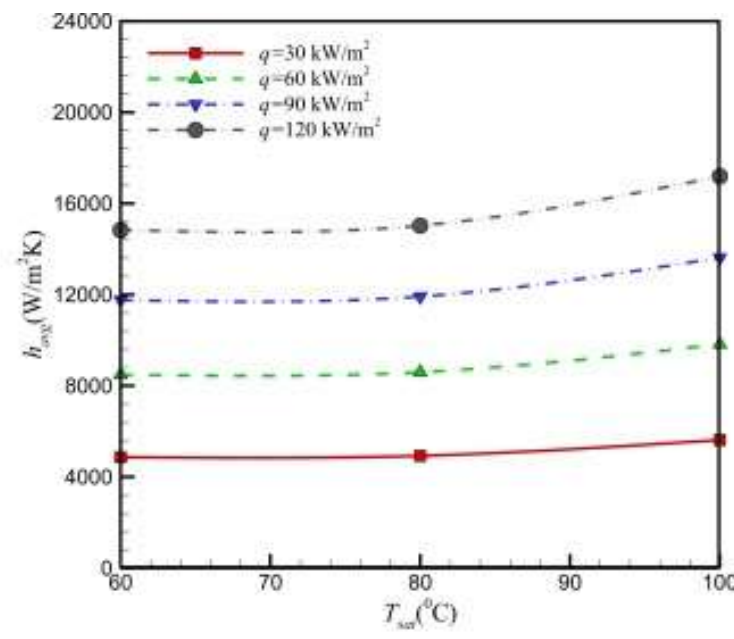

(b)

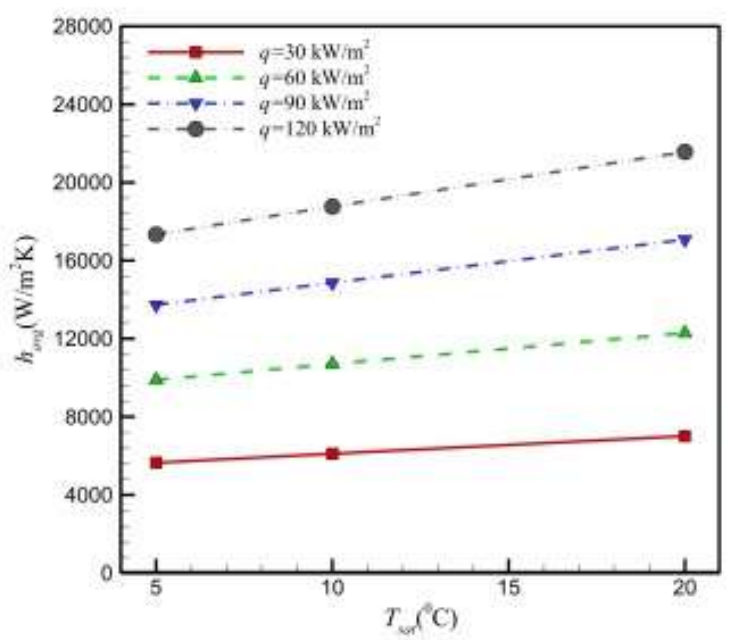

(d)

Figure 5. Effect of saturation temperature on the overall heat transfer coefficient for: (a) Water, (b) Ethanol, (c) R134a, (d) R22.

To justify the increase in the $H T C$ with the saturation temperature, contours of the vapour volume fraction are illustrated at various saturation temperatures in Figs. 6 and 7. According to these figures, the level of the vapour volume fraction increases when the saturation 

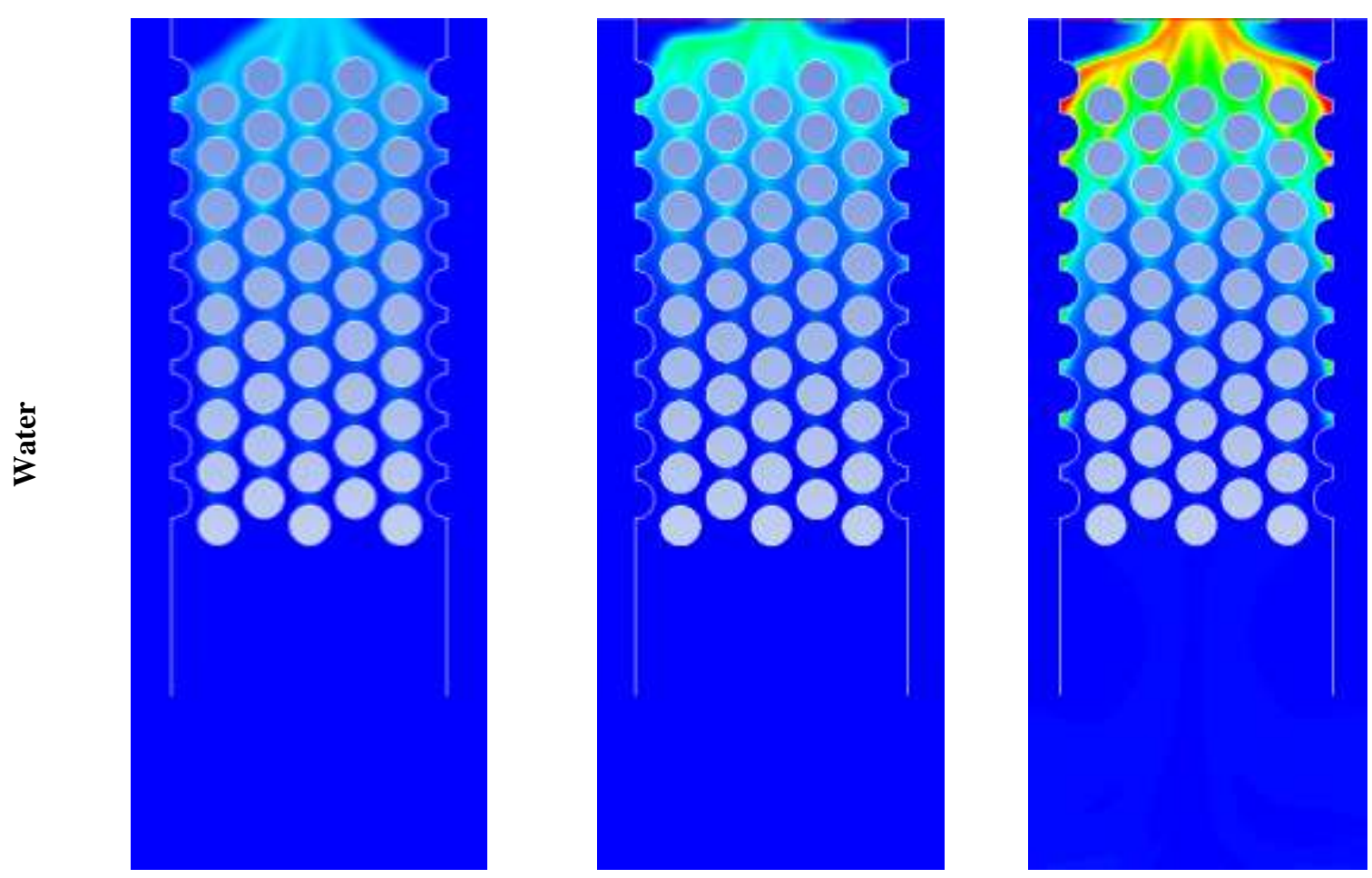

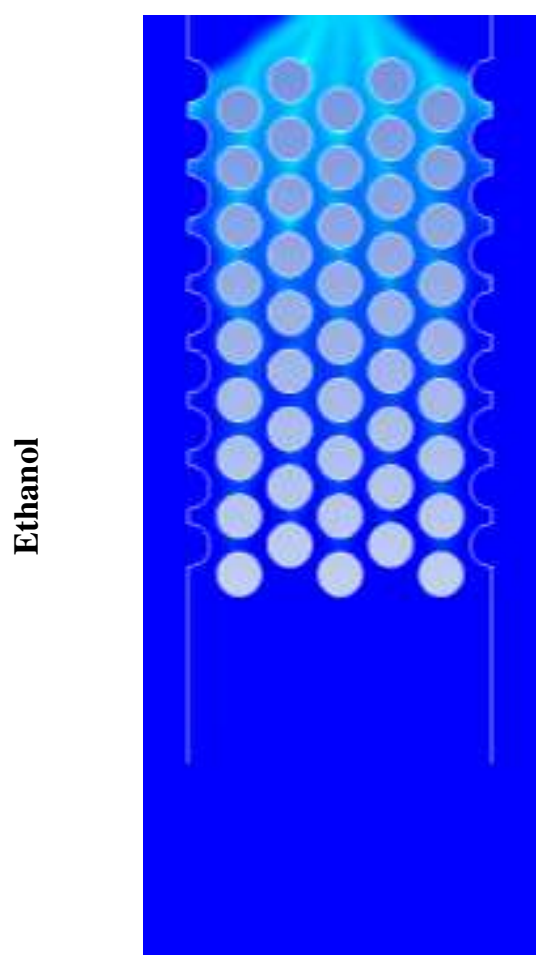

$T_{\text {sat }}=100{ }^{\circ} \mathrm{C}$

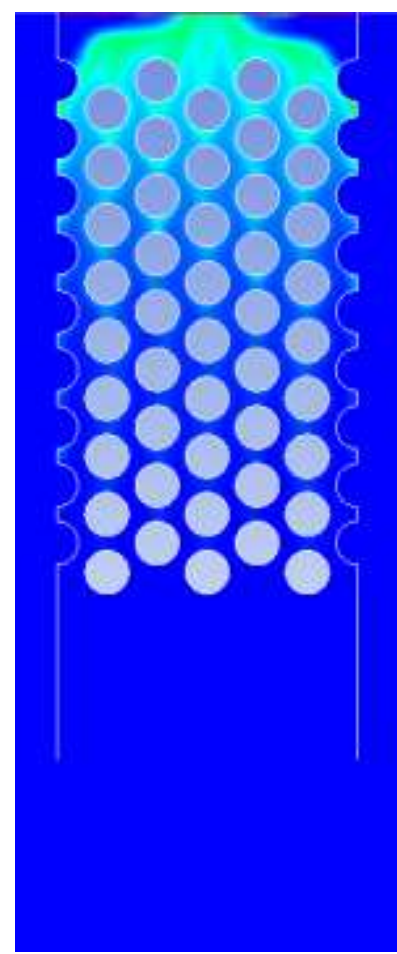

$T_{\text {sat }}=80^{\circ} \mathrm{C}$

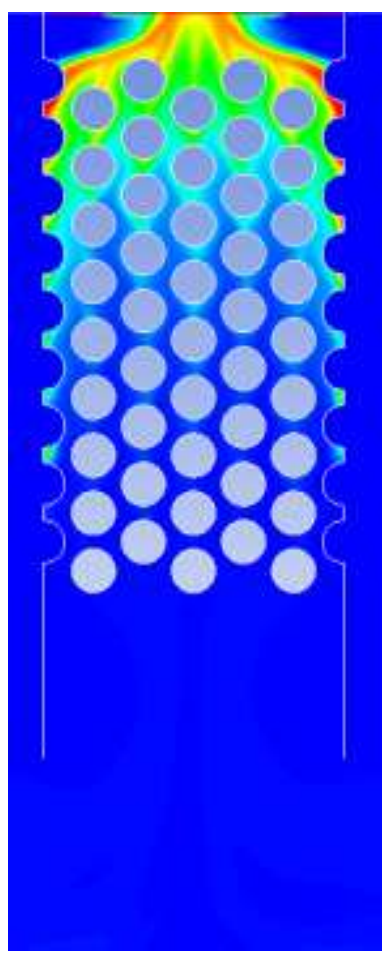

$T_{\text {sat }}=60^{\circ} \mathrm{C}$

Figure 6. Contours of vapour volume fraction for water and ethanol at $q=60 \mathrm{~kW} / \mathrm{m}^{2}$ and different values of saturation temperature. 

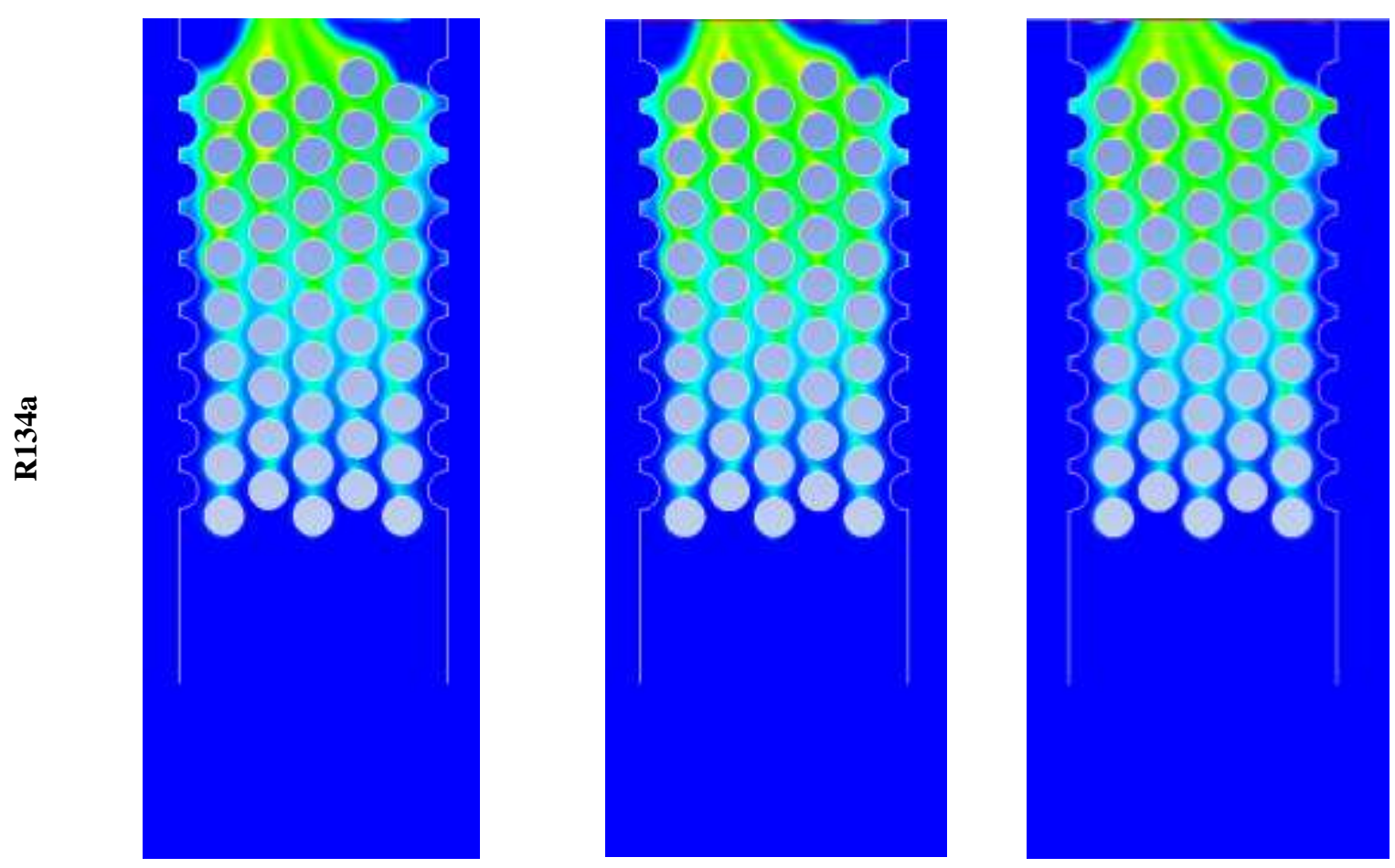

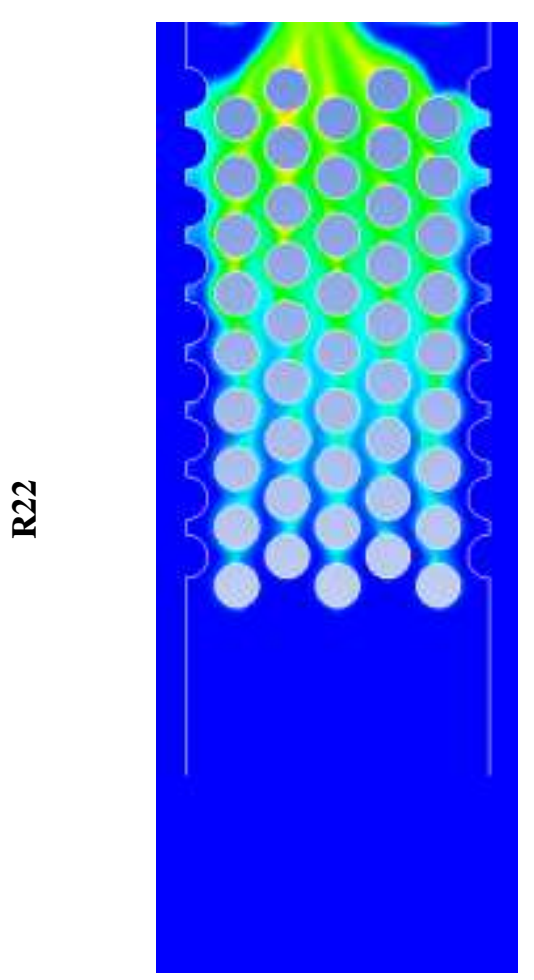

$T_{\text {sat }}=20^{\circ} \mathrm{C}$

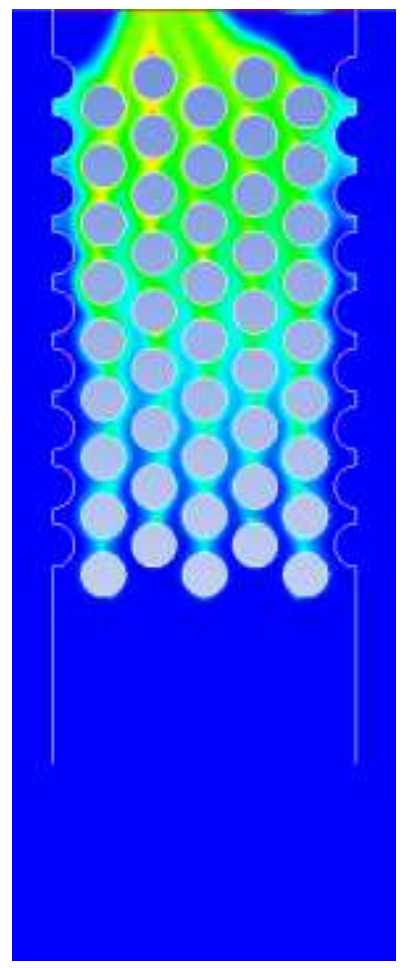

$T_{\text {sat }}=10^{\circ} \mathrm{C}$

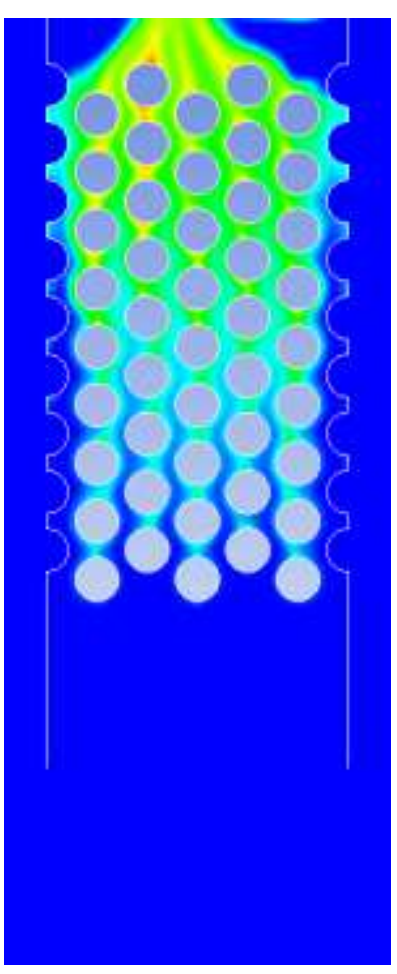

$\boldsymbol{T}_{\text {sat }}=5^{\circ} \mathrm{C}$

Figure 7. Contours of vapour volume fraction for R134a and R22 at $q=90 \mathrm{~kW} / \mathrm{m}^{2}$ and different values of saturation temperature.

temperature (or equivalently the saturation pressure) reduces. This means that larger bubbles with a lower departure frequency are formed when the saturation pressure decreases. These 
larger bubbles interrupt the natural circulation of the liquid towards the tube surface and reduces the heat transfer coefficient. The formation of larger bubbles in the lower saturation pressures could also be attributed to the decrease in the boiling site density, the increase in the bubble growth and the increase in the minimum required wall superheat for bubble formation with saturation pressure reduction (Akiyama et al., 1969).

\subsection{The variation of $H T C$ within the tube bundle}

To investigate the variation of the HTC within the tube bundle, the configuration factor is used as defined between the $\mathrm{i}$-th and $\mathrm{j}$-th rows as,

$$
\xi_{i, j}=\frac{\bar{h}_{i}}{\bar{h}_{j}}
$$

Where $\bar{h}$ is the row-averaged HTC. The profile of the configuration factor along the height of the tube bundle is depicted in Figs. 8 and 9 for water, ethanol, R-134a and R22. The figures show two distinct behaviours. In the low-flux region, larger than unity configuration factors are observed and the HTC mostly increases along the height of the tube bundle. In contrast, for the high-flux region, the $H T C$ is nearly constant within the tube bundle, and a slight decrease in the HTC is observed along the height of tube bundle is observed, even for extremely high heat fluxes, which results in the lower than unity configuration factor, especially at the upper boundary of the flow channel, where high levels of vapour volume fractions exist. These numerical predictions are in prefect agreement with the experimental data of Hsieh et al. (2003), Da Silva et al. (2007), and Ribatski et al. (2008). 

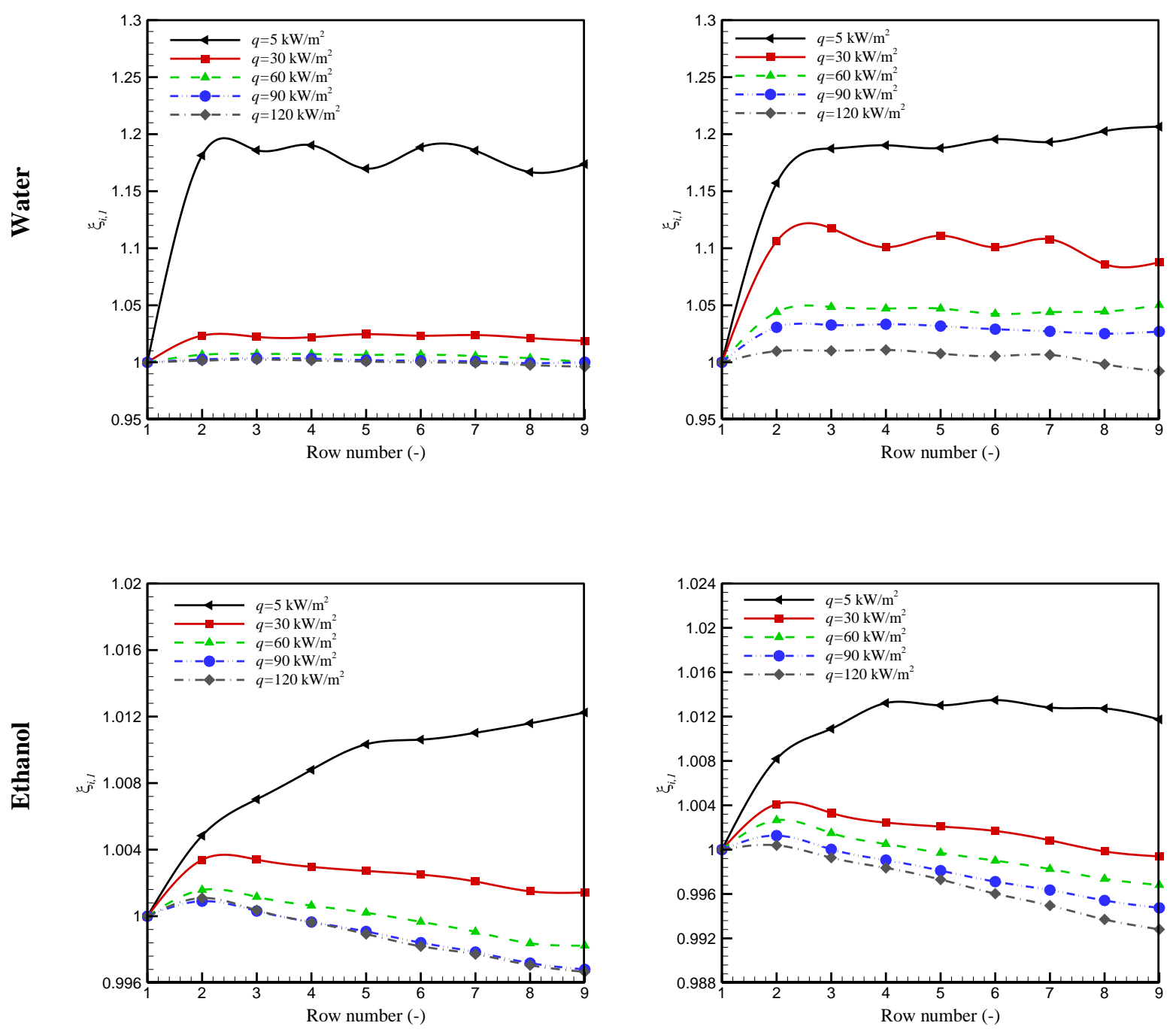

$T_{\text {sat }}=80^{\circ} \mathrm{C}$

$$
T_{\text {sat }}=60^{\circ} \mathrm{C}
$$

Figure 8. Variation of configuration factor within the tube bundle for different values of wall heat flux and for ethanol and water. 

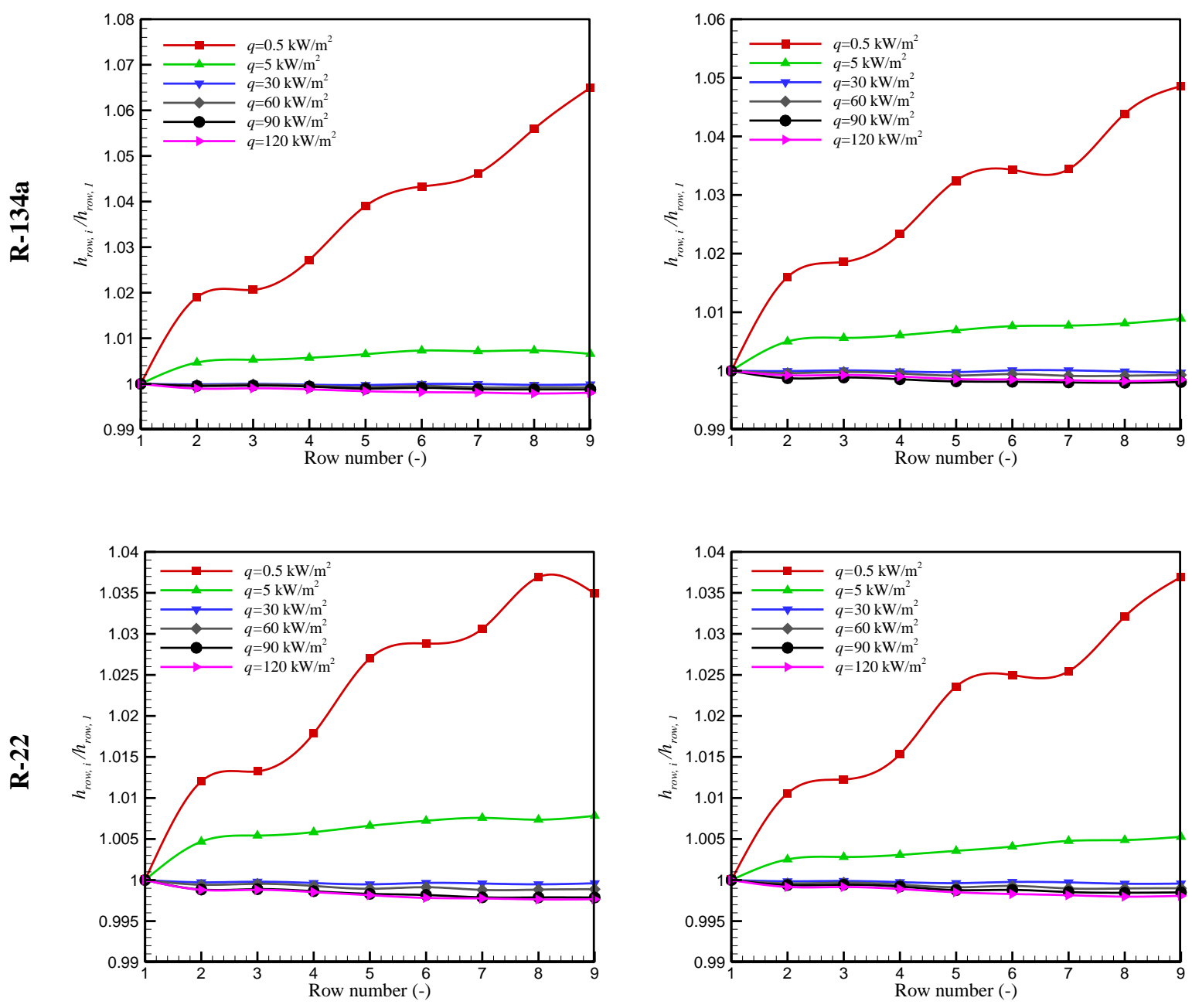

$$
T_{\text {sat }}=5^{\circ} \mathrm{C}
$$

$$
T_{\text {sat }}=10^{\circ} \mathrm{C}
$$

Figure 9. Variation of configuration factor within the tube bundle for different values of wall heat flux and for R-134a and R-22.

The aforementioned trend is reported for all working fluids at all saturation temperatures studied in the present work and could be explained noting that there are two competing mechanisms in the pool boiling heat transfer,

(a) The agitation causes the vapour bubbles to detach from the lower tubes and arrive at the surface of the upper tubes. This tends to increase the heat transfer on the upper tubes due to additional turbulence induced by the vapour bubble buoyancy-driven motion. 
(b) Bubble coalescence forms large bubbles, especially when the heat flux is increased. These large bubble slugs promote dry spots on the upper tube and reduce the heat transfer rate.

The competition between these two preceding mechanisms is portrayed in Fig. 10, where the variation in the configuration factor between the first and last tube rows is depicted as a function of the heat flux for three saturation temperatures. Moreover, in Table 3, the bundle effect (the ratio of the overall heat transfer coefficient of the tube bundle to the HTC for an isolated tube with an identical heat flux) is given for all working fluids. It can be seen for water at various saturation temperatures that when the wall heat flux is lower than $60 \mathrm{~kW} / \mathrm{m}^{2}$, the first mechanism is dominant and greater than unity values of the configuration factor are obtained for the tube bundle. The effect of vapour bubble agitation intensifies when the saturation temperature reduces. For larger heat fluxes, the second mechanism prevails and the configuration factor tends to unity.

For ethanol, R-134a and R-22, the threshold heat flux after which the bundle effect vanishes is approximately $30 \mathrm{~kW} / \mathrm{m}^{2}$. For these three working fluids, no concise conclusion could be drawn concerning the effects of the saturation temperature on the bundle effect. However, the variation in the configuration factor with the heat flux and saturation temperature is more vigorous for ethanol in comparison to the refrigerants. For the two refrigerant R-134a and R22 , a sharp decrease in the configuration facture is observed at very low heat fluxes, which is proceeded by an asymptotic behaviour. Ultimately in this study, the largest configuration factor and bundle effect belongs to water at the saturation temperature of $60{ }^{\circ} \mathrm{C}$. 
Table 3. Bundle effect for different working fluid at multiple saturation temperatures

\begin{tabular}{|c|c|c|c|c|c|c|c|c|c|c|c|c|}
\hline \multirow[b]{2}{*}{$\begin{array}{c}\text { Saturation } \\
\text { Temperature } \\
\left({ }^{\circ} \mathrm{C}\right)\end{array}$} & \multicolumn{3}{|c|}{ Water } & \multicolumn{3}{|c|}{ Ethanol } & \multicolumn{3}{|c|}{ R134a } & \multicolumn{3}{|c|}{$\mathbf{R 2 2}$} \\
\hline & 100 & 80 & 60 & 100 & 80 & 60 & 20 & 10 & 5 & 20 & 10 & 5 \\
\hline $\begin{array}{c}\text { Heat flux } \\
\left(\mathrm{kW} / \mathrm{m}^{2}\right)\end{array}$ & \multicolumn{12}{|c|}{ Bundle effect } \\
\hline 0.5 & --- & --- & --- & --- & --- & --- & 1.0243 & 1.0279 & 1.0351 & 1.0161 & 1.0201 & 1.0224 \\
\hline 5 & 1.0833 & 1.1474 & 1.2441 & 1.0064 & 1.0085 & 1.0107 & 1.0035 & 1.0062 & 1.0056 & 1.0031 & 1.0034 & 1.0058 \\
\hline 30 & 1.0074 & 1.0200 & 1.0909 & 1.0013 & 1.0022 & 1.0015 & 0.9991 & 0.9999 & 0.9999 & 0.9998 & 0.9997 & 0.9997 \\
\hline 60 & 1.0025 & 1.0049 & 1.0409 & 1.0001 & 0.9999 & 0.9995 & 0.9984 & 0.9995 & 0.9995 & 0.9996 & 0.9993 & 0.9992 \\
\hline 90 & 0.9994 & 1.0014 & 1.0263 & 0.9995 & 0.9989 & 0.9980 & 0.9983 & 0.9985 & 0.9992 & 0.9987 & 0.9990 & 0.9985 \\
\hline 120 & 0.9993 & 0.9999 & 1.0045 & 0.9994 & 0.9988 & 0.9970 & 0.9986 & 0.9989 & 0.9986 & 0.9985 & 0.9987 & 0.9984 \\
\hline
\end{tabular}




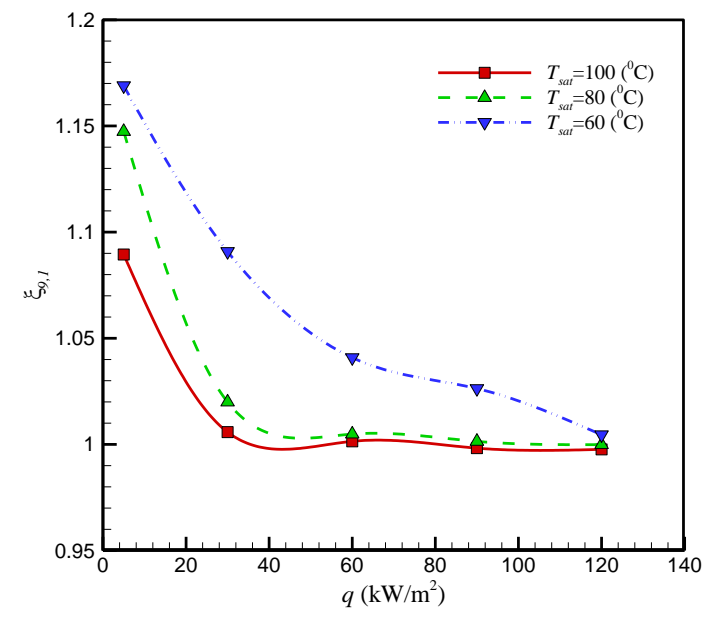

(a)

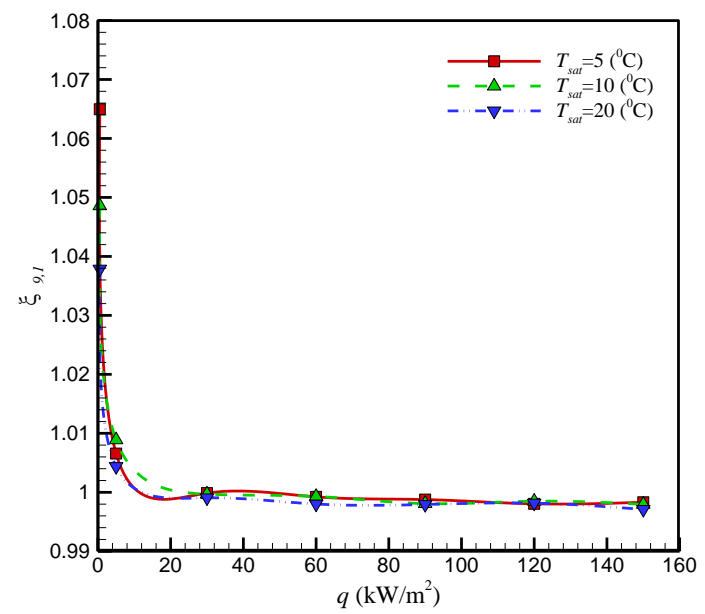

(c)

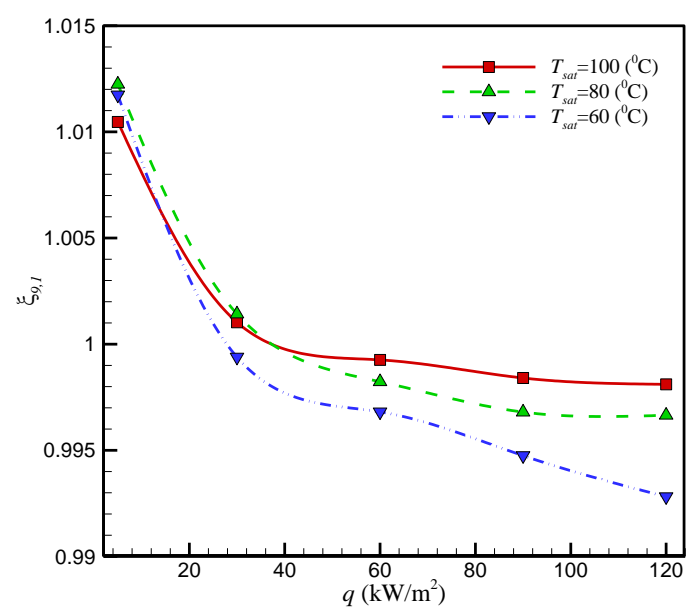

(b)

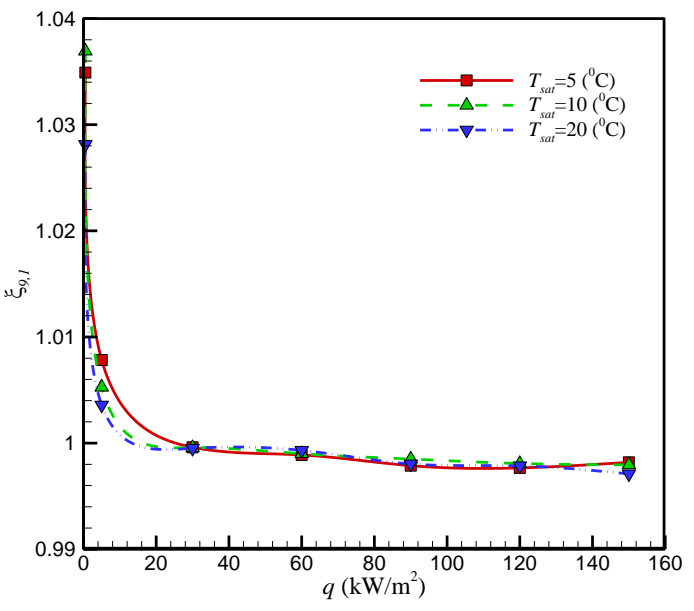

(d)

Figure 10. Last to first row configuration factor at three saturation temperatures for: (a) Water, (b) Ethanol, (c)

$$
\text { R134a and (d) R22. }
$$

\subsection{The effect of working fluid}

The pool boiling heat transfer performance of water and ethanol are compared in Fig. 11. According to this figure, at the same saturation temperature, the heat transfer coefficients of ethanol are larger than the corresponding values for water. This is attributed to the higher vapour pressure of ethanol with respect to water at an identical temperature. Subsequently, greater wall superheating temperatures are presented for water. Moreover, the difference 


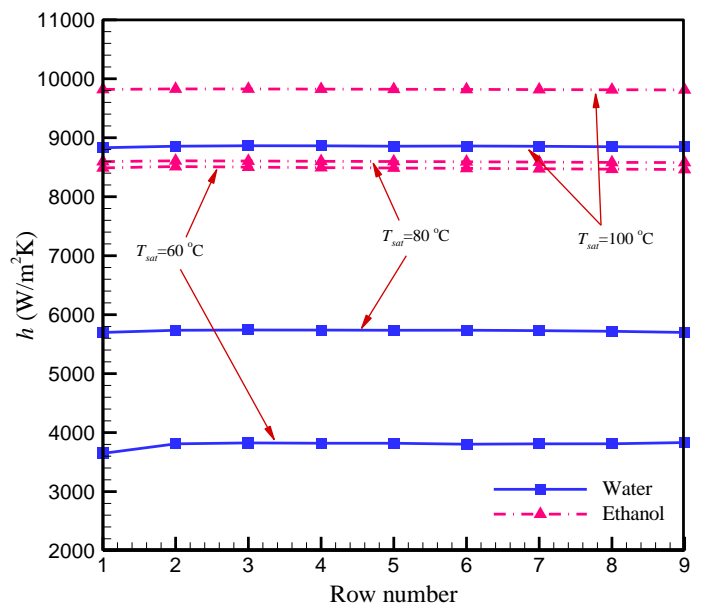

(a)

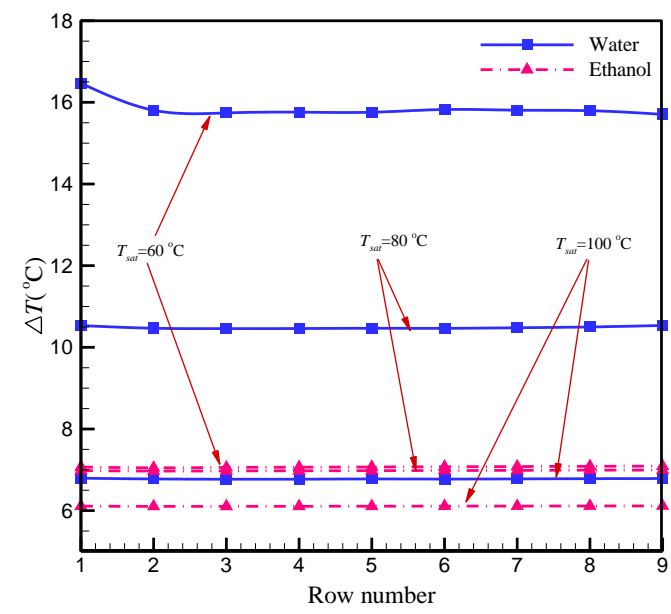

(c)

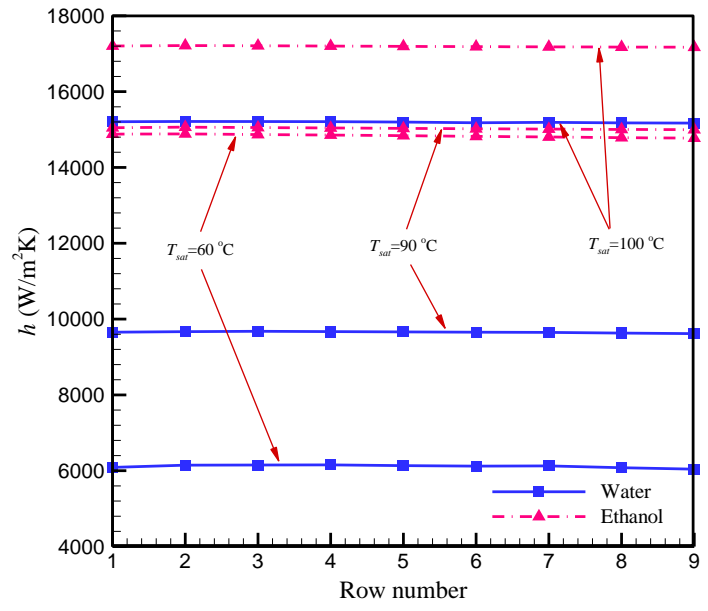

(b)

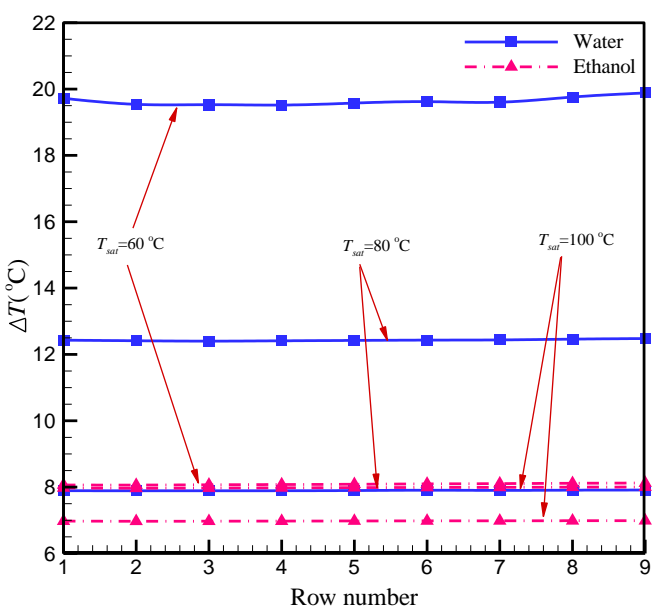

(d)

Figure 11. Comparison between pool boiling heat transfer of water and ethanol: (a) $H T C$ at $60 \mathrm{~kW} / \mathrm{m}^{2}$, (b) $H T C$ at $120 \mathrm{~kW} / \mathrm{m}^{2}$, (c) Wall superheat at $60 \mathrm{~kW} / \mathrm{m}^{2}$, (d) Wall super heat at $120 \mathrm{~kW} / \mathrm{m}^{2}$. 


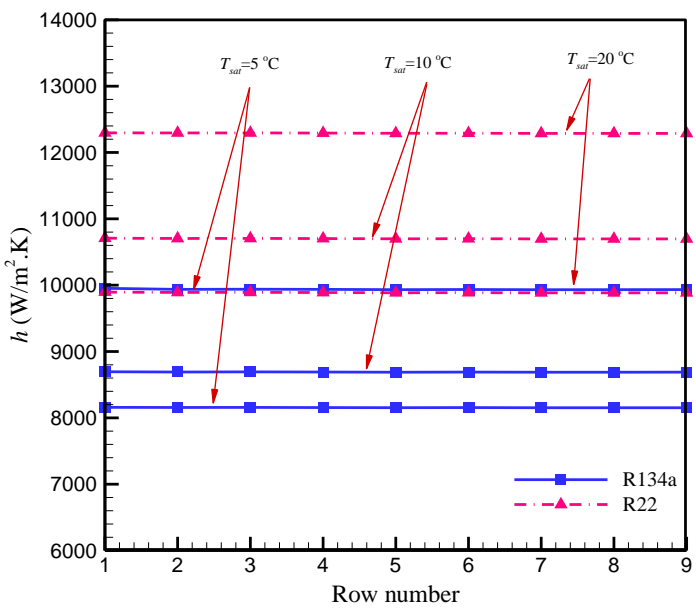

(a)

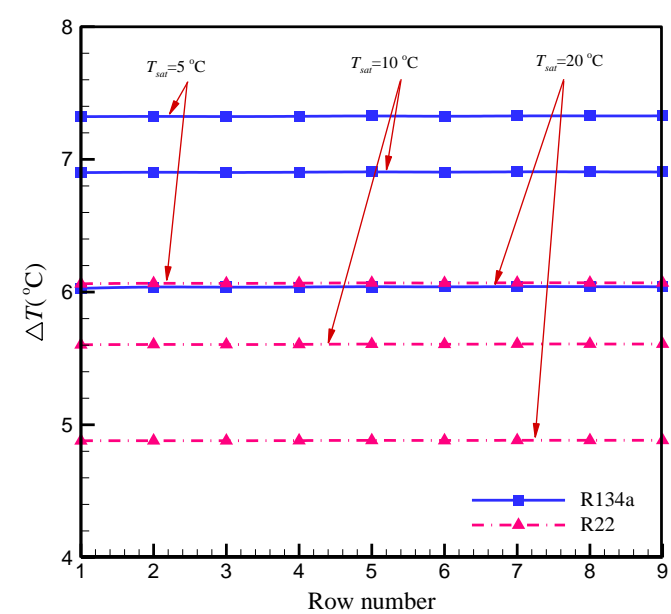

(c)

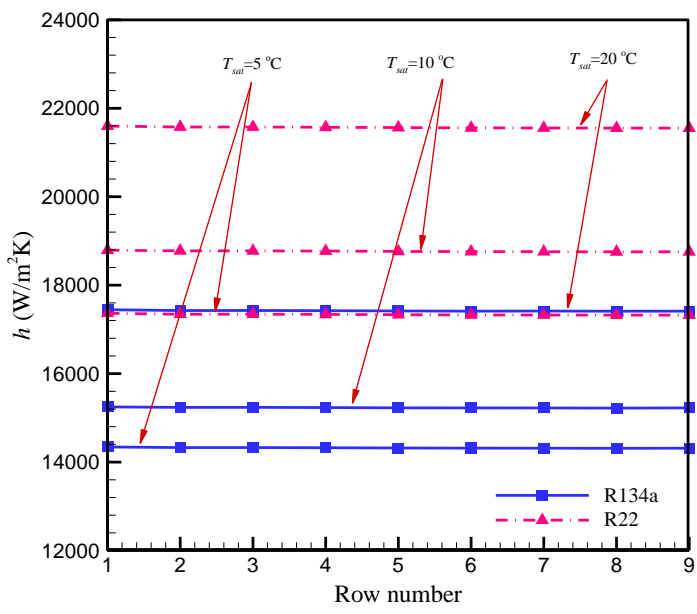

(b)

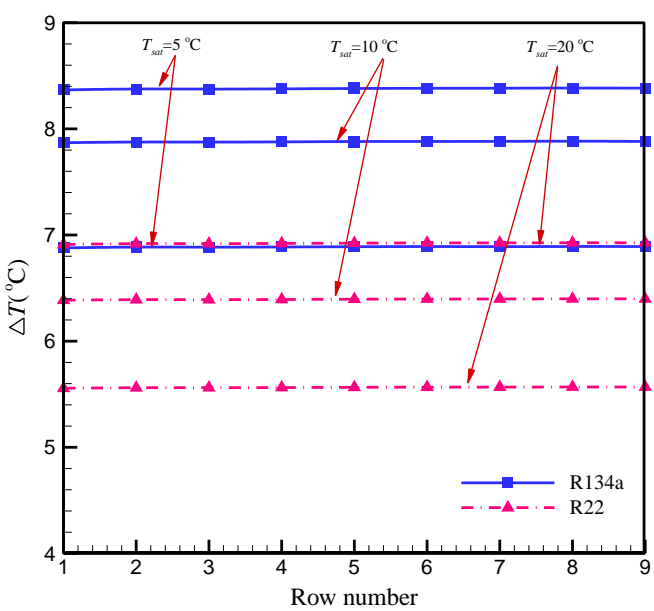

(d)

Figure 12. Comparison between pool boiling heat transfer of R134a and R22: (a) $H T C$ at $60 \mathrm{~kW} / \mathrm{m}^{2}$, (b) $H T C$ at $120 \mathrm{~kW} / \mathrm{m}^{2}$, (c) Wall superheat at $60 \mathrm{~kW} / \mathrm{m}^{2}$, (d) Wall super heat at $120 \mathrm{~kW} / \mathrm{m}^{2}$.

between the heat transfer rate for water and ethanol reduces as the temperature increases. In contrast, the distinction between the thermal performances of water and ethanol in pool boiling becomes more evident when the wall heat flux increases. The same comparison is drawn between R-134a and R22 in Fig .12 and the superiority of R22 is reported for the pool boiling heat transfer on staggered tube bundles when the boiling occurs at the same saturation temperature. 


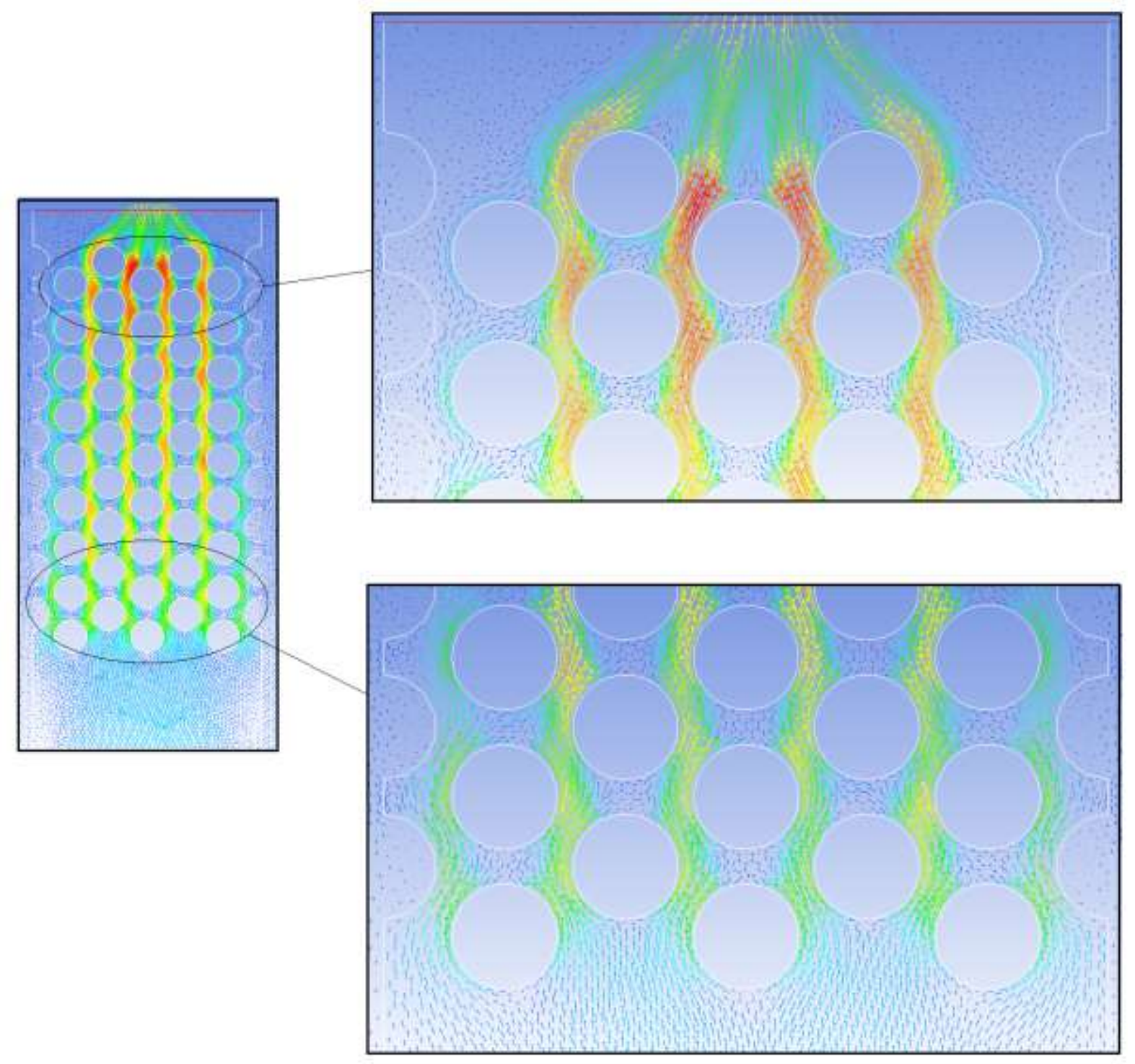

Figure 13. Velocity vectors for R22 at $5 \mathrm{~kW} / \mathrm{m}^{2}$ and saturation temperature of $5{ }^{\circ} \mathrm{C}$.

\subsection{Velocity and temperature fields}

As a final note, in this section, the velocity and temperature fields are examined for pool boiling on a tube bundle. As can be seen in Fig. 13, where the velocity vectors are depicted, the buoyance driven flow is channelized through a wavy flow passage confined by the tube surfaces. The maximum velocity exists in the middle of the flow domain and the velocity increases along the height of tube bundle. According to Fig. 14, the maximum temperature exists at the top of tube bundle, where the fluid velocity is low and the sliding vapour bubbles 
prevent the liquid from reaching the tube surface. Moreover, the variation in the temperature is fairly similar in different rows, except for the last row, where the outflow distorts the velocity and temperature fields.

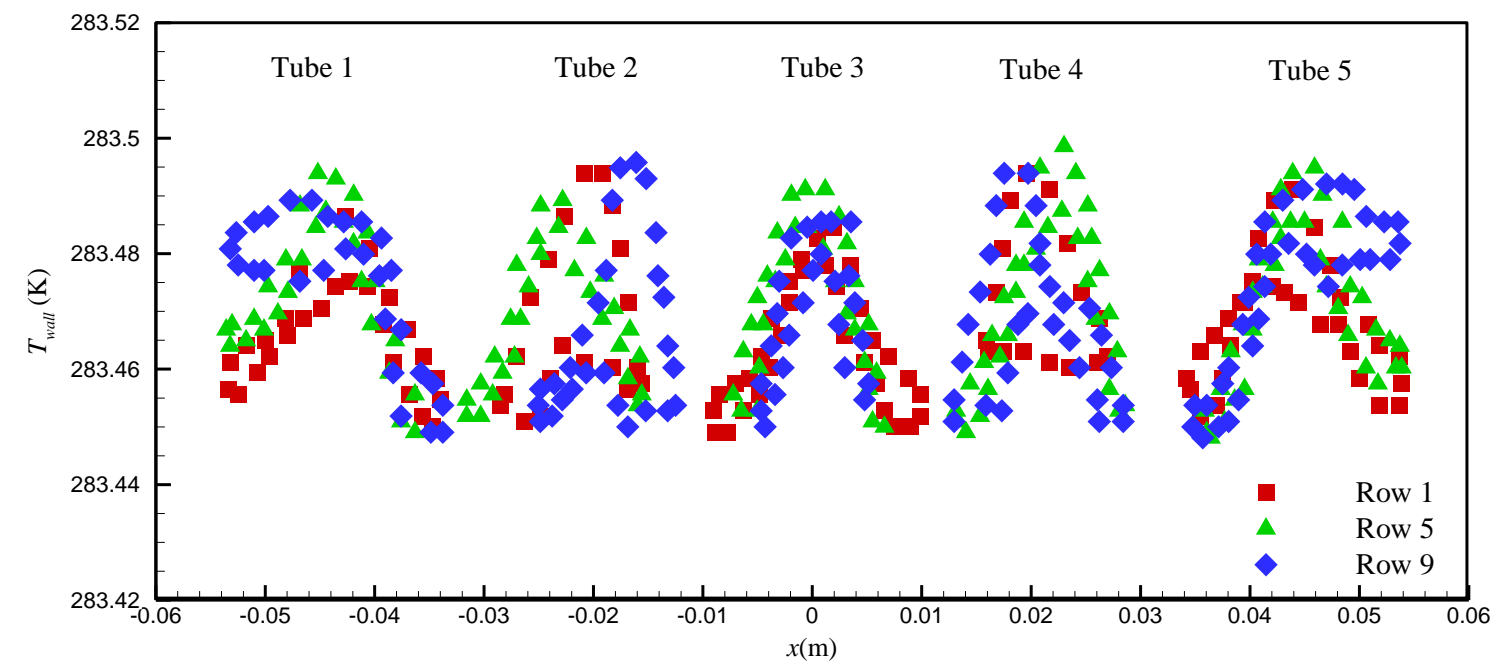

Figure 14. Temperature profiles for $\mathrm{R} 22$ at $5 \mathrm{~kW} / \mathrm{m}^{2}$ and saturation temperature of $5{ }^{\circ} \mathrm{C}$.

\section{Conclusion}

In this study, pool boiling fluid flow and heat transfer is numerically investigated on a staggered tube bundle. An Eulerian-Eulerian description of the two-phase flows is coupled with the RPI model for boiling on solid surfaces to capture the phase change phenomenon in the absence of forced fluid motion. Ample numerical results are presented for different working fluids at multiple saturation temperatures and the following conclusions were reached:

I. Using an Eulerian-Eulerian method accompanied by the RPI model for boiling heat transfer could accurately predict the heat transfer coefficient for pool boiling on isolated tubes and tube bundles. The desirable agreement between numerical results and experimental measurements corroborates this deduction. 
II. Pool boiling heat transfer coefficients for tube bundles monotonically increases with the saturation temperature and pressure. This increases is more significant for water, and for R134a and R22, a linear trend is observed.

III. When the wall heat flux is smaller than $60 \mathrm{~kW} / \mathrm{m}^{2}$ for water and smaller than $30 \mathrm{~kW} / \mathrm{m}^{2}$ for the other working fluids, the heat transfer coefficient increases along the tube bundle height. Therefore, for this low-flux zone, the values of configuration factor and the bundle effect are greater than unity.

IV. As the wall heat flux exceeds a certain threshold, the heat transfer coefficient remains approximately constant in the tube bundle and the bundle effect vanishes.

V. At the same saturation temperature, ethanol has a better thermal performance compared to water.

VI. Between the R-134a and R-22, R-22 has the greater heat transfer coefficient at an identical temperature.

\section{References}

Ahmadpour, A., Noori Rahim Abadi, S. M. A., Kouhikamali, R., 2016. Numerical Simulation of two phase gas-liquid flow through a smooth expansion/contraction. Int. J. Multi. Flow, 79, 31-49.

Akiyama, M., Tachibana, F., Ogawa, N. 1969. Effect of pressure on bubble growth in pool boiling, Bulletin of JSME. 12, 1121-1128.

Antal, S.P., Lahey, R.T., Flaherty, J.E., 1991. Analysis of phase distribution in fully developed laminar bubbly two-phase flow, Int. J. Multi. Flow. 17, 635-652.

Aprin, L., Mercier, P., Tadrist, L., 2011. Local heat transfer analysis for boiling of hydrocarbons in complex geometries: A new approach for heat transfer prediction in staggered tube bundle, Int. J. Heat Mass Transf., 54, 4203-4219. 
Avetissian, A. R., Philippov, G. A., Zaichik, L. I., 2005. The effect of turbulence on spontaneously condensing wet-steam flow, Nuc. Eng. and Des., 235, 1215-1223.

Avetissian, A. R., Philippov, G. A., Zaichik, L. I., 2008. Effects of turbulence and inlet moisture on two-phase spontaneously condensing flows in transonic nozzles, Int. J. Heat Mass Transf., 51, 4195-4203.

Barber, J., Brutin, D., Sefiane, K., Tadrist, L., 2010. Bubble confinement in flow boiling of FC-72 in a rectangular microchannel of high aspect ratio, Exp. Therm. Fluid Sci., 34, $1375-1388$.

Burns, A. D., Frank, T., Hamill, I., Shi, J. M., 2004. The Favre averaged drag model for turbulent dispersion in Eulerian multi-phase flows, Fifth International Conference on Multiphase Flow, ICMF-2004, Yokohama, Japan.

Clift, R., Grace, J. R., Weber, M. E., 1978. Bubbles, drops and particles, Academic Press, New York, NY.

Cole, R., 1960. A photographic study of pool boiling in the region of the critical heat flux, AIChE 6, 533-542.

Da Silva, E.F, Jabardo, J.M.S, Ribatski, G., 2007. An experimental study on the effect of tube position and spacing in a bundle pool boiling heat transfer. Proceedings of COBEM, Brasilia.

Del Valle, V. H., Kenning, D. B. R., 1985. Sub-cooled flow boiling at high heat flux, Int. J. Heat Mass Transf. 28, 1907-1920.

Drew, D.A., 1983. Mathematical modeling of two-phase flow, Annual Review of Fluid Mechanics. 15, 261-291.

Fujita, Y., Hidaka, S., 1998. Effect of Tube bundles on nucleate boiling and critical heat flux, Heat Transfer-Asian Research. 27, 312-325. 
Gupta, A., 2005. Enhancement of boiling heat transfer in a $5 \times 3$ tube bundle, Int. J. Heat Mass Transf., 48, 3763-3772.

Gupta, A., Kumar, R., Kumar, V., 2010. Nucleate pool boiling heat transfer over a bundle of vertical tubes, Int. Commun. Heat Mass Transf., 37, 178-181.

Hsieh, S-S., Huang, G-Z., Tsai, H.-H, 2003. Nucleate pool boiling characteristics from coated tube bundles in saturated R-134a, Int. J. Heat Mass Transf., 46, 1223-1239

Jung, D., Kim, Y., Ko, Y., Song, K., 2003. Nucleate boiling heat transfer coefficients of pure halogenated refrigerants, Int. J. Refrig., 26, 240-248.

Kang, M. G., 2016. Pool boiling heat transfer from an inclined tube bundle, International J. Heat Mass Transf., 101, 445-451.

Krasowski, K., Cieslinski, J.T., 2011. Nucleate pool boiling heat transfer from small horizontal smooth tube bundles, Transactions of the Institute of Fluid-Flow Machinery. 123, 85-98.

Kumar, S., Mohanty, B., Gupta, S.G., 2002. Boiling heat transfer from a vertical row of horizontal tubes, Int. J. Heat Mass Transf., 45, 3857-3864.

Kurul, N., Podowski, M. Z., 1991. On the modelling of multidimensional effects in boiling channels, Proceedings of the 27th National Heat Transfer Conference, Minneapolis, MN.

Lemmert, M., Chawla, L. M., 1977. Influence of flow velocity on surface boiling heat transfer coefficient, in E. Hahne, U. Grigull, Heat transfer in boiling (237-247), Academic Press and Hemisphere.

Minocha, N., Joshi, J. B., Nayak, Ar. K., Vijayan, P. K., 2016. 3D CFD simulation of passive decay heat removal system under boiling conditions: Role of bubble sliding motion on inclined heated tubes, Chemical Engineering Science, 15, 245-265. 
Mudawar, I., Anderson, T.M., 1990. Parametric investigation into the effects of pressure, subcooling, surface augmentation and choice of coolant on pool boiling in the design of cooling systems for high-power-density electronics chips, J. Elec. Pack., 112, 375382.

Ribatski, G., Jabardo, J.M.S., Da Silva, E.F., 2008. Modeling and experimental study of nucleate boiling on a vertical array of horizontal plain tubes, Exp. Therm. Fluid Sci., $32,1530-1537$.

Ribatski, G., Thome, J.R., 2006. Nucleate boiling heat transfer of R134a on enhanced tubes, Appl. Therm. Eng., 26, 1018-1031.

Ribatski, G., Thome, J.R., 2007. Two-phase flow and heat transfer across horizontal tube bundles-a review, Heat Transfer Eng., 28, 508-524.

Swain, A., Das, M.K, 2014. A review on saturated boiling of liquids on tube bundles, Heat Mass Transf., 50, 617-637.

Tomiyama, A., 1998. Struggle with computational bubble dynamics, Third International Conference on Multiphase Flow Lyon, France, 8-12 June.

Yeoh, G.H., Tu, J., 2010. Computational techniques for multi-phases flows, Elsevier UK. 